\title{
Teaching Math for Emergent Bilinguals: Building on Culture, Language, and Identity
}

\author{
JI-YEONG I AND RICARDO MARTINEZ
}

IOWA STATE UNIVERSITY DIGITAL PRESS

AMES, IA 


\section{(ㄷ) (1) (2) (2)}

Teaching Math for Emergent Bilinguals: Building on Culture, Language, and Identity by Ji-Yeong I and Ricardo Martinez is licensed under a Creative Commons Attribution-NonCommercial-ShareAlike 4.0 International License, except where otherwise noted.

Suggested citation: I, Ji-Yeong, and Ricardo Martinez. 2020. Teaching Math for Emergent Bilinguals: Building on Culture, Language, and Identity . Ames, IA: Iowa State University Digital Press. https://doi.org/10.31274/isudp.2020.57

Suggested attribution: Teaching Math for Emergent Bilinguals: Building on Culture, Language, and Identity by Ji-Yeong I and Ricardo Martinez is available under a Creative Commons Attribution NonCommercial ShareAlike 4.0 International License.

Published by the Iowa State University Digital Press, a division of the University Library at Iowa State University.

701 Morrill Rd, Ames, IA 50011, USA

E-mail: digipress@iastate.edu 


\section{Contents}

Preface $\quad$ V

Ji-Yeong I

Introduction 1

English Language Learners and Emergent Bilinguals

ji-Yeong I and Ricardo Martinez

1. Emergent Bilinguals in Math Class

ji-Yeong I and Ricardo Martinez

2. Culturally Sustaining Pedagogy for/with Emergent Bilinguals

Ricardo Martinez and Ji-Yeong I

3. EB-focused Strategies and Challenging Tasks

Ji-Yeong I and Ricardo Martinez

4. Power \& Participation of Mathematical Discussion 36

Ricardo Martinez and Ji-Yeong I

5. Translanguaging \& Word Problems

ji-Yeong I and Ricardo Martinez

6. Connecting Learned Mathematics to Emergent Bilingual Families and Community

Ricardo Martinez and Ji-Yeong I 



\title{
Preface
}

\author{
JI-YEONG I
}

\section{The Beginning-}

During my first year at Iowa State University in 2015, I had a chance to apply for an internal grant, which was designated for developing an innovative new course. My dear colleague, Dr. Christa Jackson, suggested for me to create an online course on teaching mathematics to Emergent Bilinguals, given my research expertise. Prior to this, there was no such course in the field that integrated the following three crucial components: teaching, mathematics, and Emergent Bilinguals.

With Dr. Jackson's encouragement, I started to do research on developing an effective online course for teachers and met with Dr. Katy Swalwell, who had successfully launched a new online course in social studies education, Teaching and Learning Iowa History. Dr. Swalwell's online course was developed and delivered via the learning management platform Canvas.net in a multifaceted structure for preservice teachers, in-service teachers, and others with interest in Iowa's history. For preservice teachers who are enrolled in a university-based teacher preparation program or graduate students who are interested in this topic, this course provides graduate-level credits for completing all modules. In-service teachers who are current or former classroom teachers, or district leaders, can choose to take this course for one, two, or three credits for renewing their teaching license in Iowa. In addition, any Canvas users who are interested in teaching mathematics for Emergent Bilinguals can come and explore the materials, although they are not mandated to submit assignments. This flexible structure appealed to me and I was eager to apply the same structure to the online course to my proposed mathematics education course.

Thankfully, Dr. Swalwell also introduced me to Clyciane Michelini, an EdTech \& Distance Education Coordinator, who turned out to be a great addition to my course development and management team. With Ms. Michelini and Dr. Jackson's help, I formed a team to develop this online course. My doctoral advisee, Ricardo Martinez, also joined this team and co-authored this ebook (he has now become Dr. Martinez, a faculty member at the University of Nebraska-Lincoln). Our idea was to design an innovative and interactive online course aiming to provide concrete and applicable content about teaching mathematics for culturally and linguistically diverse students. This vision of creating an equitable math education course enabled us to secure the College Human Science Innovative Teaching Initiatives grant. 


\section{The Initial Stage-}

Our preparation to develop this $100 \%$ asynchronous online course took about one year. We first offered EDUC 502/593G Teaching Mathematics to English Language Learners in the spring semester of 2017 through Canvas.net. The initial design of this course focused on providing not only general teaching principles but also delivering authentic strategies that teachers can apply to their classrooms. The two principles stated by Moschkovich (2010) were the central pillars of the initial design.

1. Treat students' language as a resource, not a deficit.

2. Address much more than vocabulary, and support EBs' participation in mathematical discussions as they learn English.

We chose Beyond Good Teaching (Celedon-Pattichis \& Ramirez, 2012), published by NCTM, as the textbook because this edited book includes valuable contents of research-based teaching approaches to support Emergent Bilinguals and their teachers. Based on these fundamental perspectives, the initial design of the course included six modules, in addition to the orientation module as follows:

1. Who are ELLs?

2. Culturally Responsive Teaching

3. ELL-focused Strategies

4. Academic Language

5. Mathematical Discussion

6. ELL-focused Lesson Planning

This online course, Teaching Mathematics to English Language Learners (TM-ELL), has received a warm response and has become popular within Canvas Network. Since Canvas Network is worldwide, many mathematics and English teachers from multiple countries have enrolled in this course, and some of them have actively participated. In the summer of 2019, for instance, we had more than 500 students from over 10 countries including the Philippines, Romania, India, Venezuela, Vietnam, Morocco, Mongolia, Indonesia, Panama, Cambodia, Paraguay, and Myanmar enrolled in the TM-ELL course, and the enrollment numbers keep increasing.

\section{The Updating Stage-}

We observed how the initial course design worked for four semesters through the pre- and post- survey responses from participants. Overall, their feedback was positive in terms of learning and gaining knowledge. However, we also found some limitations in the initial 
design and needed to strengthen the content with respect to building culturally relevant, responsive, and sustaining classrooms. Moreover, although we love the textbook, Beyond Good Teaching, it was necessary to include more recent resources in teaching mathematics and Emergent Bilinguals. For instance, the field currently suggests using the term Emergent Bilinguals (EBs) instead of English Language Learners (García \& Kleifgen, 2010).

The revision or update process began in 2019. Fortunately, we received another internal grant provided by the Iowa State University Library for updating the online course content as well as writing a digital textbook, which is this book. The focus of the course content revision was to emphasize and strengthen valuing students' different cultures and languages. Hence, two new modules/chapters were added: Translanguaging and Community Cultural Wealth. In addition, the module on Culturally Responsive Teaching was updated to Culturally Sustaining Pedagogy (CSP), which has a critical role as an umbrella framework for the entire course. The revised course consists of seven modules, and accordingly, this book has seven chapters:

- Introduction: Who are EBs?

- Chapter 1: EBs in math class

- Chapter 2: Culturally sustaining pedagogy

- Chapter 3: EB-focused strategies and challenging tasks

- Chapter 4: Power \& participation in mathematical discussion

- Chapter 5: Translanguaging with a focus on word problems

- Chapter 6: Connecting mathematics to families and communities of EBs.

We hope you enjoy this book, and when you complete this book, you can fulfill the following goals:

1. Identify the various needs and capabilities of EBs in learning mathematics.

2. Use EBs' own languages as a resource, not a deficit, and learn to use multiple modes of communication.

3. Implement research-based strategies to teach EBs in order to maximize their learning through cognitively demanding mathematical activities and differentiate your teaching practice correspondingly to your EBs.

4. Support EBs' participation in mathematical discussions as meaningful community members while they learn English.

5. Look beyond the school and connect to EBs' parents and community to expand mathematical learning in and outside the classroom.

Ji Yeong I

Iowa State University, Ames, IA, USA

Fall 2020 



\section{Introduction}

\section{English Language Learners and Emergent Bilinguals}

JI-YEONG I AND RICARDO MARTINEZ

Determine if each of the following statements are True or False. Make sure you answer all four questions.

An interactive H5P element has been excluded from this version of the text. You can view it online here:

https://iastate.pressbooks.pub/teachingmath/?p=4\#h5p-13

Did you find the True or False statements interesting? Now we will ask you to brainstorm the following questions to get ready to read this chapter: ${ }^{1}$

BUMBLEBEE Pre-reading Questions

(Building Understanding in Mathematics By Leveraging Emergent Bilinguals' as Equals in Education)

1. How do you define English language learners?

2. How does your school or district define/identify English language learners?

3. What challenges and obstacles do you think English language learners encounter in an English-only school and how do you think it impacts their lives? What do you think causes those challenges?

1. Within the following chapters, you will encounter the acronym BUMBLEBEE and questions associated with it. BUMBLEBEE is an affirmative acronym which stands for "Building Understanding in Mathematics By Leveraging Emergent Bilinguals' as Equals in Education.” Before reading each chapter, we will ask you some BUMBLEBEE pre-reading questions to help frame the chapter and draw upon your teaching philosophy. After reading the chapter, you will encounter some postreading BUMBLEBEE questions to reflect on what you have learned and brainstorm how to move forward with this new knowledge. 


\section{Why ELLs?}

English language learners (ELLs) — the students whose fluent languages do not include English-often face multiple academic learning challenges when English is the only instructional language in their schools or when their school has no support for their native language.

The issues surrounding ELLs are complicated and have multiple layers. It is not only about language. The naïve belief-obtaining English proficiency will resolve ELLs' educational issues-may lead to naïve teaching approaches for ELLs, such as providing simple translation or holding grade-level curricula until they master English. The misguided approach for teaching ELLs may result in the continuous gap of the mean scores in nationwide mathematics assessments (NAEP, 2013, 2015, 2017) between ELLs and non-ELLs.

Our first step to unravel the complicated issue is to understand who ELLs are.

\section{Who Are ELLs?}

It is difficult to define ELLs because the existing definitions of ELLs vary by states, districts, and schools. The inconsistency increases when we add the different assessment tools used to identify ELLs and the variations in the identification of ELLs.

"A prerequisite for understanding English learners is a systematic analysis of their demographic characteristics and of whether and how these characteristics differ from those of their non-EL peers. These are NOT simple matters.” (NASEM, 2017, p. 63)

The US Department of Education provides this interactive online document to explain the characteristics of ELL students. While keeping in mind that the dataset includes many limits, which are addressed in the document. Explore the information contained in the Our Nation's English Learners.

If you like to learn more about the demographics of ELLs, refer to this recent document, Promoting the Educational Success of Children and Youth Learning English (NASEM, 2017), especially Chapter 3, “The Demography of the English Learner Population.”

We will share some interesting facts from this document. The figure below shows where the new immigrants originally came. While mass media have focused on immigrants from Latin America, the largest group of recent immigrants are from Asian countries (approximately $50 \%$ as Figure 1 shows). Asian Americans are now the fastest-growing, highest-income, and best-educated racial/ethnic group in the U.S. (Pew Research Center, 2012).

2 | Introduction 


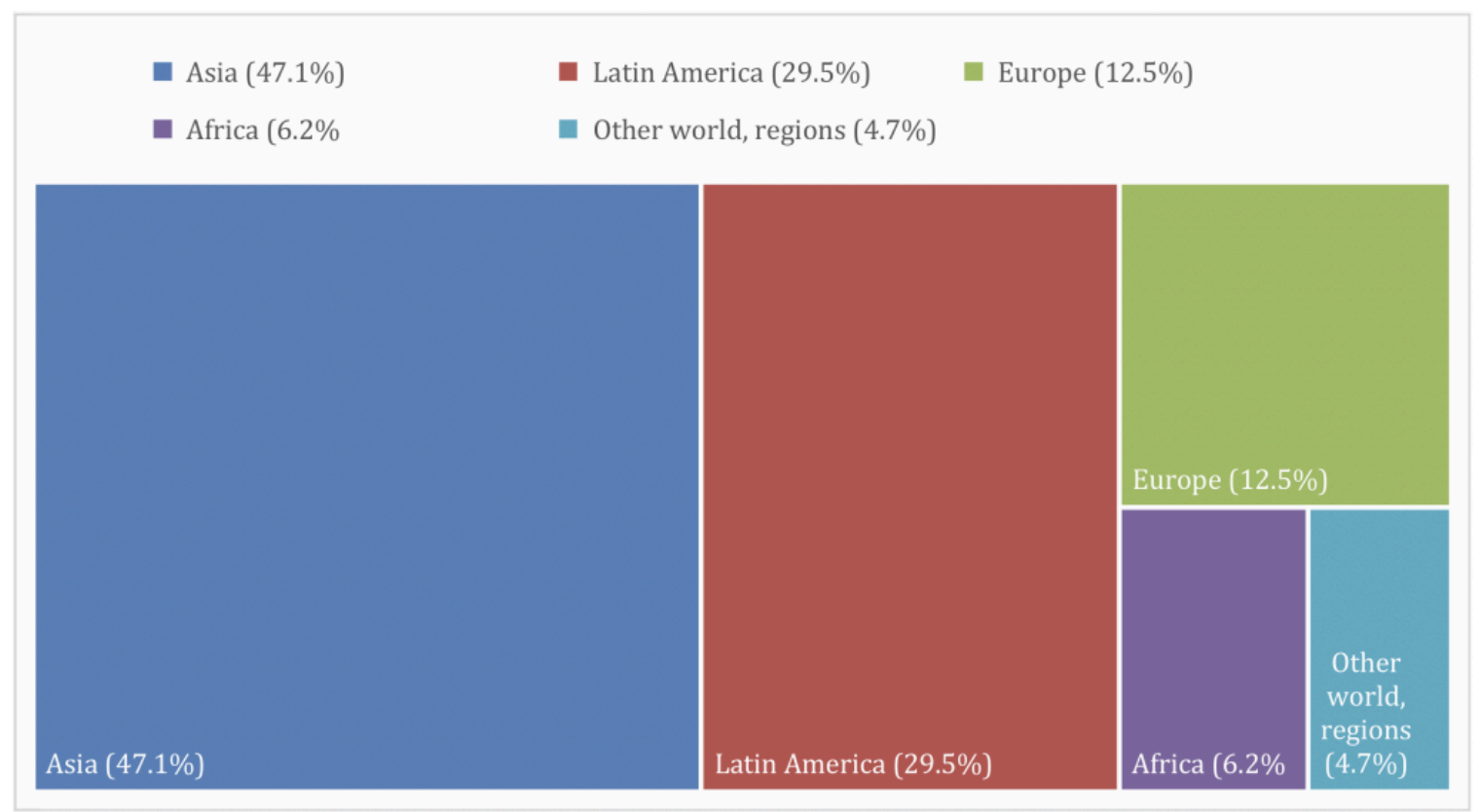

Figure 1: Region of origin of new immigrants to the U.S. in 2013 (Jensen et al., 2015)

It is well known that the majority of ELLs in the US are US-born. However, the distributions vary along with age. It is important to note the following two implications from NASEM (2017).

1. Not all high school foreign-born ELLs are newcomers. Foreign-born ELLs arrive in the U.S. at a younger average age (4.97 years) relative to foreign-born non-ELs (7.6 years), but their ELL status stays until they are in high school. This implies "foreign-born ELs appear to find themselves in disadvantaged structural contexts that limit their access to services needed to improve their English proficiency” (p. 74).

2. The US-born ELLS are almost 50\% of the ELL population at age 18 . For 18 years, they do not receive enough opportunities to access to achieve English proficiency (and/or academic success) in the current US school structure).

The NASEM (2017) Chapter 3 summarizes three core facts of the ELL populations (p. 98), which are shared here.

1. The cultures, languages, and experiences of English learners are highly diverse and constitute assets for their development, as well as for the nation.

2. Many English learners grow up in contexts that expose them to a number of risk factors (e.g., low levels of parental education, low family income, refugee status, homelessness) that can have a negative impact on their school success, especially when these disadvantages are concentrated.

3. As the population of English learners continues to diversify, limitations of current 
data sources compromise the capacity to provide a more comprehensive description of the population's characteristics for policy makers, administrators, and teachers who have responsibilities for their education.

\section{Why Emergent Bilinguals?}

You must notice various terms are used for ELLs: LEP, English learner (ELs), ESL, ELD, etc. We need to choose one term to have clear conversations throughout this book. So, let's begin with the story behind these names.

Before 2015, the USA federal government officially used "Limited English Proficient (LEP)" to call individuals who do not speak English as their primary language and who have a limited ability to read, speak, write, or understand English. No Child Left Behind (NCLB) had described these students as those "whose difficulties in speaking, reading, writing, or understanding the English language may be sufficient to deny the individual the ability to meet the State's proficient level of achievement on State assessments" (2001). The official definition in Every Student Succeeds Act (ESSA) is of students "ages 3-21, enrolled in elementary or secondary education, born outside of the United States or speaking a language other than English in their homes, and not having sufficient mastery of English to meet state standards and excel in an English-language classroom” (Title III, Elementary and Secondary Education Act [ESEA], as cited in National 23 Research Council, 2011, p. 5). In 2015, ESSA simply called these students English Learners (ELs). Still, ELL or EL is a common term used in many states, including Iowa.

Recently, researchers (e.g., Ofelia García) have challenged these labels by suggesting to transform our view towards these culturally and linguistically diverse students. Let's check the following facts first.

- As García noted (2006a), ELLs are "only the tail of the elephant,” 2.7 million of the 10.9 million bilingual and multilingual children in the U.S.

- "By focusing only on the elephant's tail, or those students who are not proficient in English, we lose sight of the incredible potential of the millions of bilingual and multilingual children in this country who can become national resources in building a peaceful coexistence within a global society and helping the United States remain economically viable in an increasingly multilingual world.” (García \& Kleifgen, 2010, pp. 10-11)

When we use ELLs and ELs, we easily forget or neglect the fact that they are bilingual (or even multilingual). Emergent Bilinguals are suggested since these students are becoming bilinguals. The word "bilingual/multilingual" implies a positive and intellectual asset. While 
the terms LEP/ELL/EL focus on what the students cannot do, this term Emergent Bilingual focuses on what they can do even before they become fluent in English.

Here is the reason that García and Kleifgen (2018) prefer to use Emergent Bilingual in their book Educating emergent bilinguals: Policies, programs, and practices for English learners.

State and local educational authorities prefer the term English language learner (ELL) or English learner (EL) because these are protected labels. That is, once students are given this label, their English learning needs are recognized and funds are allotted to their education. But the ELL/EL label has serious limitations: It devalues other languages and puts the English language in a sole position of legitimacy. It also focuses solely on the development of what is referred to as "academic English," ignoring other parts of students' language and education.

We prefer, and use here, the term emergent bilingual because it has become obvious to us that much educational inequity is derived from obfuscating the fact that a meaningful education will not only turn these English learners into English proficient students but more significantly, into bilingual and multilingual students and adults. Emergent bilingual most accurately indexes the type of student who is the object of our attention- those whose bilingualism is still emerging. (p. 27)

We also prefer to use Emergent Bilingual who will be Proficient Bilingual sooner or later. Here we use "bilingual" as an inclusive term that includes multilingual who can use more than two languages. With using Emergent Bilingual, we (teachers, parents, policymakers, educators, and people) can pursue different educational goals. Rather than merely learning English and becoming a fluent English speaker, our educational goal for Emergent Bilinguals is to support them to be Proficient Bilinguals and successful academic learners by providing them with a high-quality curriculum because they have the potential to accomplish by using both languages.

Here's one more emphasis on using Emergent Bilinguals, which is related to Chapter 7.

Giving emergent bilinguals a name that does not focus on their limitations means that their family and community language practices are seen as an educational resource. Instead of assigning blame to parents and community for language practices that may not include English, the school can begin to see the parents and community as the experts in the students' linguistic and cultural practices, which are the basis of all learning. As a result, family and community members will be able to participate in the education of their students from a position of strength, not from a position of limitations. (García \& Kleifgen, 2018, p.28)

We used ELLs in the beginning because ELL is the official term in many states and we want to avoid any possible confusion of using other terms. After this point, we will use Emergent Bilinguals in this book. We may sometimes use ELL or EL for a specific reason in our context, but we want to make it clear that Emergent Bilingual is the main term we use for this book. 
Why don't you go back to the beginning of this chapter and try the True or False activity? With the knowledge you obtained from reading this chapter, you may have a different result.

\section{Overview of the Book}

This book consists of three parts. The goal of the first part is building fundamental knowledge such as defining terms, exploring how theoretical backgrounds evolved, and the main framework. In this introduction, we provide the definition of English language learners and introduce Emergent Bilinguals as a shared language that will be used in the entire book.

Chapter 1 describes the multiple challenges Emergent Bilinguals generally experience in mathematics classrooms. Through the challenges, we can see that mathematics is built on a certain culture and language system and how teaching and learning mathematics is related to language. When we accept the political and cultural nature of mathematics and understand the role of language in learning mathematics, we can recognize why Emergent Bilingual students struggle in mathematics classrooms. The dual challenges of learning mathematics and English is not the only barrier Emergent Bilinguals experience in school. The pervasive deficit view towards Emergent Bilinguals may seriously influence their learning.

Chapter 2 points out this issue and explores culturally sustaining pedagogy, which is a core lens of this book. From the theoretical background of culturally sustaining pedagogy to culturally responsive mathematics teaching lesson analysis tool, this chapter aims to shine the intersection of culturally sustaining pedagogy, Emergent Bilinguals, and mathematics.

The second part of the book focuses on teaching practices designed for Emergent Bilinguals in mathematics classrooms. Chapter 3 is all about teaching strategies. We try to make connections between the provided examples of teaching strategies and previously introduced principles and theoretical lenses.

Chapter 4 is particularly devoted to participation in mathematical discussions. The power distribution between teachers and students and Emergent Bilinguals and non-Emergent Bilinguals is discussed with questioning how to encourage all students' participation. Another significant theory, translanguaging, is explored in Chapter 5, which is closely connected to culturally sustaining pedagogy. We believe translanguaging can shift and challenge the current teaching paradigm, especially with Emergent Bilinguals. Moreover, we discuss a way to help Emergent Bilinguals access word problems using language analysis, representations, and translanguaging approaches.

The last part of the book goes beyond school. Chapter 6 connects mathematical learning to

6 | Introduction 
students' families and communities. We introduce the Community Cultural Wealth Model to explore various capitals that Emergent Bilinguals may have and teachers should be aware of in order to utilize them for teaching. For this structure, we strongly recommend readers follow the order of chapters and try to make connections among the contents of chapters. Each chapter will begin with Thinking Questions Before Reading and end with Thinking Questions After Reading. We made and present these questions in this way on purpose. To maximize your own learning, we hope you pause reading for a while to deeply think about these questions in each chapter.

\section{BUMBLEBEE Post-reading Questions}

1. How are the facts you read in this chapter different from or similar to what you thought in the beginning?

2. Do you have any changed perspectives or expectations related to Emergent Bilinguals through this module reading?

\section{References}

Committee on Fostering School Success for English Learners: Toward New Directions in Policy, Practice, and Research, Board on Children, Youth, and Families, Board on Science Education, Division of Behavioral and Social Sciences and Education, Health and Medicine Division, \& National Academies of Sciences, Engineering, and Medicine. (2017). Promoting the Educational Success of Children and Youth Learning English: Promising Futures (R. Takanishi \& S. L. Menestrel, Eds.). https://doi.org/10.17226/24677

García, O., \& Kleifgen, J. A. (2018). Educating emergent bilinguals: Policies, programs, and practices for English learners (Second edition). New York: Teachers College Press.

Jensen, E.B., Knapp, A., Borsella, C., and Nestor, K. (2015). The Place of Birth Composition of Immigrants to the United States: 2000 to 2013. Washington, DC: U.S. Census Bureau.

Pew Research Center. (2012). The Rise of Asian Americans. Washington, DC: Pew Research Center Social \& Demographic Trends. Available: https://www.pewresearch.org/social-trends/ wp-content/uploads/sites/3/2012/06/The-Rise-of-Asian-Americans.pdf [June 20, 2016]. 



\title{
I. Emergent Bilinguals in Math Class
}

\author{
JI-YEONG I AND RICARDO MARTINEZ
}

- Answer the following questions. Make sure you answer all four questions.

An interactive H5P element has been excluded from this version of the text. You can view it online here:
https://iastate.pressbooks.pub/teachingmath/?p=5\#h5p-14

* Source: Adapted from Celedon-Pattichis \& Ramirez (2012).

BUMBLEBEE Pre-Reading Questions

1. As a math teacher, do you think that supporting EBs' English learning is part of your responsibility? Why or why not?

2. Is mathematics a universal language? Do you think mathematical concepts and notations are the same in all countries?

3. Do you think EBs have less difficulty in math classes than other subject classes? Why or why not?

"Of greatest importance, in relation to placement for STEM learning, is their prior knowledge about STEM subjects, but children are not typically assessed for their content knowledge when entering U.S. schools. Instead, their identification and course placement, at least at the secondary level, is typically determined by their level of English proficiency.” (NASEM, 2018, p. 27)

Mathematics course placement should depend on students' mathematical knowledge and performance, but in reality, other factors interfere with the decision of class placement of EBs (and many other marginalized students). For EBs in the United States, their course placement is typically determined by their level of English proficiency (NASEM, 2018). Placing EBs in math classes by their English proficiency harmfully impacts their learning because EBs in low-track mathematics courses are not usually provided with enough opportunities to learn rigorous mathematics. If EBs achieve English proficiency and move to non-ELL status, they are often placed in low-track mathematics classes again because they did not learn grade-level math up until that point (Umansky, 2016). We need to break this negative cycle that systemically fails our students. We must not withhold a rigorous 
math curriculum from EBs until they achieve English proficiency. Mathematical learning and English development must be pursued simultaneously in math classes. This chapter discusses how we can work towards these dual goals.

\section{Dual Goal Challenges}

These dual goals are not only EBs' challenge but their teachers' challenge as well. Mathematics teachers may feel burdened when they encounter EBs struggling to understand the language used in a math lesson or worksheet because teaching language is not their expertise (however, many states, including Iowa, require all content teachers to be equipped with disciplinary literacy methods). When we recommend math teachers improve EBs' learning in both math and English, we do not mean that math teachers should teach English grammar. Rather, we encourage teachers to step away from correcting grammatical and spelling errors and instead focus on EBs' mathematical ideas. To do so, we support following Moschkovich's (2010) recommendations:

1. Treat students' language as a resource, not a deficit: When your EBs use their home language, their everyday language with their own accents and/or emergent pronunciation, do not perceive it as a deficiency or obstacle for those who cannot use English well. Instead, use students' languages as a resource to support their growing proficiency in their home language, English, and mathematics.

2. Address much more than vocabulary and support EBs' participation in mathematical discussions as they learn English: Math teachers teach mathematical terminologies, such as function, variable, or fraction. But when they do, they should not just teach these words. Instead, they need to build the mathematical concept or meaning of a term with how to read and write the term and how to use it successfully in a sentence. The process for building a conceptual understanding requires various language activities, such as discussion, explanation, justifying, comparison, etc. Through these high-level language activities, rather than simply memorizing words, EBs can develop their English proficiency while they learn mathematics.

These two principles are based on a common view: EBs are capable. They can do rigorous mathematics, and they can do high-level language activities. Hence, teachers should focus on EBs' mathematical ideas and reasoning, allowing them to productively grapple with high-level language activities while they make sense of mathematics. In other words, math teachers should provide EBs with ample opportunities to engage in both challenging mathematics tasks and high-level language activities. Math teachers teach mathematical concepts and procedures, but they do not have to focus on English itself, especially lowlevel linguistic skills such as accurate pronunciation, vocabulary, or spelling. You probably have seen EBs (and non-EBs too) become silent after their spelling or pronunciation is corrected because they do not want to make more mistakes. Note: if you really want to help 
EBs with their English spelling or pronunciation, you can model good examples rather than directly correcting their mistakes.

To engage EBs in mathematical reasoning and high-level language skills, setting learning objectives for both mathematical and language learning is essential. The next section explains what a language objective is and how to write an effective language objective for EBs in math classrooms.

\section{Language Objective}

Each lesson has its objectives or learning targets that a teacher aims for students to achieve at the end of the lesson. A mathematics lesson has mathematics objectives, such as "students will be able to distinguish a function from non-function relationships by using graphs.” For EBs, teachers can also have language objectives (Echevarria, Vogt, \& Short, 2004), such as "students will be able to explain that a function is a relationship between two sets where one input corresponds to only one output by engaging in a class discussion, writing about functions, and drawing graphs.” To pursue dual goals for teaching math to EBs, setting objectives for both content and language is necessary.

Jennifer Himmel explains what a language objective is and how to write it as follows (for an in-depth look please, refer to Colorin Colorado),

Language objectives are lesson objectives that specifically outline the type of language that students will need to learn and use in order to accomplish the goals of the lesson. Quality language objectives complement the content knowledge and skills identified in content area standards and address the aspects of academic language that will be developed or reinforced during the teaching of grade-level content concepts (Echevarria \& Short, 2010).

These objectives involve the four language skills (speaking, listening, reading, and writing), but they can also include:

1. The language functions related to the topic of the lesson (e.g., justify, hypothesize)

2. Vocabulary essential to a student being able to fully participate in the lesson (e.g., axis, locate, graph)

3. Language learning strategies to aid in comprehension (e.g., questioning, making predictions).

The idea of language objectives initially came from the SIOP Model. SIOP stands for the Sheltered Instruction Observation Protocol, which is a framework for organizing and assessing instruction specially designed for EBs 
Here are some more tips for writing effective language objectives for EBs from Colorin Colorado:

1. Include high-level language activities where students discuss or justify, instead of only focusing on vocabulary learning (Moschkovich, 2010). This does not mean you cannot include any vocabulary learning in the objectives - teachers sometimes need to teach unknown terms. It means do not have only low-level language activities in the lesson.

2. Include productive language modes (speaking and writing), instead of just passive modes of language activities (listening and reading). By being able to see and hear students' responses, this will also help teachers assess students learning in both mathematics and language.

3. Consider an extended view of discourse, such as drawing, representations (graphs, charts, tables, etc.), and gestures.

\section{Mathematics is NOT a Universal Language}

To discuss how we can support EBs to succeed in learning both mathematics and English in a math class, we need to talk about what mathematics is. The traditional view of mathematics is that mathematics consists of numbers and symbols, and learning mathematics requires a huge amount of memorization. A common student complaint about mathematics is that mathematics is not related to their lives or the real world. This view is in the same vein as this common saying, "mathematics is a foreign language" or "mathematics is an alien language." Some may say this due to the abstract appearance of mathematics. Others may say this because they feel they will never understand mathematics. This perception also reflects their belief that mathematics has nothing to do with the language they use every day. This belief also connects to the common assumption that mathematics is culture free and language free. This false view toward mathematics is one of the reasons why EBs face difficulties in math class, as there is no reason for a teacher to differentiate a math lesson for EBs if mathematics is language free. So, here is a question for you:

\section{Is mathematics really free from culture and language?}

As you might expect, the answer is NO. The quotes below emphasize how language has an important role in mathematical learning.

It is important to recognize that the content taught in STEM subjects is not separable from the language through which the content is presented (Schleppegrell, 2007). There is no language-free content; language use always presents some content, and most 
representations of content require some language use, even with multimodal resources for meaning-making (NASEM, 2018, p. 58).

One contributing factor to the difficulty ELs [EBs] experience is that mathematics is more than just numbers; math education involves terminology and its associated concepts, oral or written instructions on how to complete problems, and the basic language used in a teacher's explanation of a process or concept (Echevarria, Vogt, \& Short, 2010, p. 1)

When teachers say EBs are doing fine in their math class, it may imply that the EBs already learned the specific math concepts in their home country. In that case, they might perform well on certain mathematical tasks-if the task does not include text-heavy content-although they may not understand what their teacher says and may not be able to verbally explain how and why they solved the task in that way. However, when EBs learn a new mathematical concept that they have not learned in their home countries, language then becomes a huge barrier because it is through language that the meaning of the new concept is delivered. If a verbal explanation is the only instructional tool, EBs will not understand the new concept, and they will soon fall behind in their math class unless their parents hire a bilingual tutor for them.

Language is not the only factor that influences EBs' learning in mathematics. A few years ago, one high school EB student, let's call her Sunni, explained what happened in her math class. She had learned how to solve quadratic equations by factoring in her home country, and the method was different from the common method used in the U.S. When she had a test on this concept, she used the method she learned in her home country. After receiving her test back, Sunni was shocked to discover that, her math teacher marked her answers wrong although the answers were correct. Even after Sunni explained how she solved the problems (she could not explain herself very well in English), the math teacher insisted she must use the method taught in the class.

You may or may not agree with Sunni's math teacher, but regardless of the teacher's decision, this is an example of the fact that mathematics is not a universal language. Not only are there different ways to read the term quadratic equation, but there are also different methods for solving quadratic equations in different cultural communities. People say 1+1=2 in any language or country, but in English, you will read the equation as "one plus one equals two" but in Korean, for instance, it will be read as “일 더하기 일은 이," which does not make any sense to non-Korean speakers.

Even writing and reading numeric symbols are different in different cultures. Perkins and Flores (2002) show many examples of the differences between the US notations and Mexican notations and the reference document provided by TODOS: MATHEMATICS FOR ALL shows the differences between the U.S. and Latin American ones. Here are some examples: 
Table 1.1 Comparison of mathematical notation between the U.S. and Latin American countries

\begin{tabular}{|c|c|c|}
\hline U.S. & $\begin{array}{l}\text { Latin American } \\
\text { Countries }\end{array}$ & Descriptions \\
\hline $9,435,671$ & 9.435 .671 & $\begin{array}{l}\text { Reading Numbers Form } 1 \\
\text { In the U.S. numbers are separated by groups of } 3 \\
\text { (otherwise known as periods) and separated by } \\
\text { commas. } \\
\text { In some Latin American countries, the point is used } \\
\text { to separate such groups. }\end{array}$ \\
\hline $9,435,671$ & 9435671 & $\begin{array}{l}\text { Reading Numbers Form } 2 \\
\text { In some Latin American countries, a space is also } \\
\text { used to separate groups of } 3 \text { and/or periods. This is } \\
\text { especially true in Argentina. }\end{array}$ \\
\hline $9,435,671$ & $9^{\prime} 435,671$ & $\begin{array}{l}\text { Reading Numbers Form } 3 \\
\text { As per the Secretaría de Educación Pública of } \\
\text { Mexico 1993, millions are separated by an } \\
\text { apostrophe, and commas separate multiples of } \\
\text { thousands. }\end{array}$ \\
\hline $9,435,671$ & $9 ; 435,671$ & $\begin{array}{l}\text { Reading Numbers Form } 4 \\
\text { The semicolon is also used in Mexico to separate } \\
\text { the millions period from the thousands period. }\end{array}$ \\
\hline-4 & -4 or $\overline{4}$ & $\begin{array}{l}\text { Negative Numbers } \\
\text { In Mexico, negative numbers may be written either } \\
\text { of two ways- } \\
\text { 1. As they are written in the U.S., with a preceding } \\
\text { negative sign, or } \\
\text { 2. With a bar over the number } \\
\text { The latter format may be confused as a repeating } \\
\text { decimal fraction. }\end{array}$ \\
\hline$\overline{3}$ or $0.333 \ldots$ &.$\hat{3}$ & $\begin{array}{l}\text { Repeating Decimals } \\
\text { In the U.S., a repeating decimal is written with a bar } \\
\text { over the digit that is repeating and/or the repeating } \\
\text { digit(s) are shown followed by three dots. } \\
\text { Some books from Mexico indicate a repeating } \\
\text { decimal with an arc rather than a line above the } \\
\text { number. }\end{array}$ \\
\hline
\end{tabular}

Different notations in Asian countries and European countries also exist. For Asian countries' mathematical notations, refer to the following table and for European notations, refer to this link: 
The Algorithm Collection Project (Long Division Algorithms Collected in the European Union)

Table 1.2: Comparison of mathematical notation between the U.S. and Asian countries (I \& Yu, 2017)

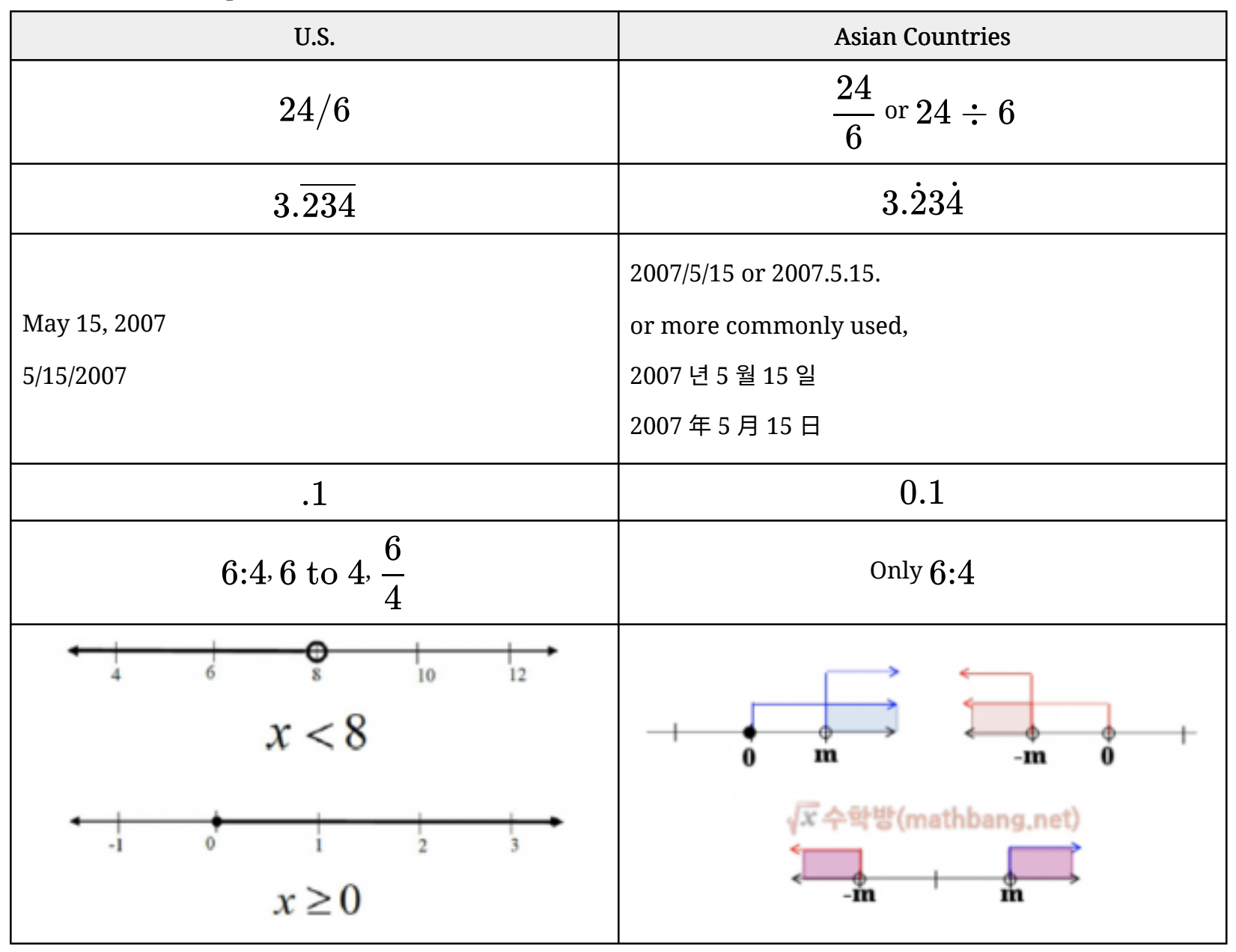

Can you see how complicated the challenges are that many EBs face in their math classes? When they cannot provide an explanation of their thinking process in English, their mathematical knowledge and performance are often devalued or not recognized, as you saw in Sunni's case. As mentioned earlier, navigating the teaching and learning of EBs is complex for both student and teacher alike, but a language objective acts as a reminder to ensure mathematics and language development can happen at the same time. The benefits of language and being able to communicate mathematically for EBs will also be discussed in later chapters. 
1. How would you react if you saw an EB using a different method to solve a mathematics task than the method you taught in your class?

2. What are some ways you can recognize and respect your EBs' differing mathematical knowledge?

\section{References}

Celedon-Pattichis, S., \& Ramirez, N. G. (Eds.). (2012). Beyond good teaching: Advancing mathematics education for ELLs. National Council of Teachers of Mathematics.

Echevarria, J., Vogt, M., \& Short, D. (2004). Making content comprehensible for English learners: The SIOP Model. Allyn and Bacon.

Moschkovich, J. N. (Ed.). (2010). Language and mathematics education: Multiple perspectives and directions for research. Information Age Pub.

National Academies of Sciences, Engineering, and Medicine (NASEM). (2018). English Learners in STEM Subjects: Transforming Classrooms, Schools, and Lives. Washington, DC: The National Academies Press. doi: https://doi.org/10.17226/25182.

Schleppegrell, M.J. (2007). The linguistic challenges of mathematics teaching and learning: A research review. Reading \& Writing Quarterly, 23(2), 139-159.

Umansky, I. M. (2016). Leveled and exclusionary tracking: English learners' access to academic content in middle school. American Educational Research Journal, 53(6), 1792-1833. https://doi.org/10.3102/0002831216675404 


\title{
2. Culturally Sustaining Pedagogy for/with Emergent Bilinguals
}

\author{
RICARDO MARTINEZ AND JI-YEONG I
}

\section{BUMBLEBEE Pre-Reading Questions}

1. As a teacher, have you considered students' language and culture as it relates to their identity?

2. How do you think students' identities may impact their mathematical learning?

3. What roles do you think students' knowledge from their home lives play in respect to enriching math lessons?

[P]retending that we can "improve" marginalized students' mathematical learning opportunities without taking into account their lived experiences, is educationally nä̈ve at best. Some of these lived experiences involve navigating different worlds (e.g., literally geographically, Mexico and the United States, as well as home and school), different languages, negative perceptions (e.g., views of immigration), fears (e.g., their "status" in the United States), and areas of expertise that grow out of these lived experiences and that may be different from our own experiences and expertise. (Civil, 2014, p.11).

We began by asking, "As a teacher, have you considered students' language and culture as it relates to their identity?" But, how about your identities? Have you thought about the complexity of your own identities in relation to your students' identities within the shared space of the classroom? In this chapter, we explore these questions by discussing culturally sustaining pedagogy (CSP) in the teaching and learning of mathematics for Emergent Bilinguals (EBs). We will begin by briefly exploring the evolution of culturally relevant pedagogies towards CSP within mathematics education. Next, we will explore the two guiding theories that built CSP, along with key characteristics of CSP. We will end by emphasizing the need to situate EBs as capable mathematical learners who have the capacity to transform the mathematics classroom, mathematics teachers, and the world. As much as you, as a teacher, interact with your students, they impact how you see your classroom. 


\section{Birth of Culturally Sustaining Pedagogy}

Culturally relevant pedagogy was theorized and came to life by Gloria Ladson-Billings (1995) to teach African American students, and consists of three key ideas:

1. Support students' academic achievement;

2. Ensure students gain and demonstrate forms of cultural competence in maintaining their own cultural history while gaining access to the dominant culture; and

3. Have students develop an understanding and critique of societal norms, which requires critical reflection in guiding action.

For more information about culturally relevant pedagogy watch a speech by LadsonBillings here:

A YouTube element has been excluded from this version of the text. You can view it online here:

https://iastate.pressbooks.pub/teachingmath/?p=55

CSP is an extension of culturally relevant pedagogy in that it explicitly connects teachers to the question, "What is the purpose of schooling in pluralistic societies?" We cannot deny that the society we are living in is no longer monocultural and monolingual, and the purpose of education needs to change. As Alim and Paris (2017) stated, "CSP seeks to perpetuate and foster - to sustain - linguistic, literate, and cultural pluralism as part of schooling for positive social transformation” (p. 1). According to Django Paris (2012), who coined the term CSP,

The term culturally sustaining requires that our pedagogies be more than responsive or relevant to the cultural experiences and practices of young people-it requires that they support young people in sustaining the cultural and linguistic competence of their communities while simultaneously offering access to dominant cultural competence. Culturally sustaining pedagogy, then, has as its explicit goal of supporting multilingualism and multiculturalism in practice and perspective for students and teachers (p. 95).

In this quote, Paris reflected that culturally "relevant” pedagogy has been watered down, and the third goal of culturally relevant pedagogy, which emphasizes students' critical reflection on the political nature or power, has not been well implemented. Hence, he extended and revitalized culturally relevant pedagogy by proposing CSP.

When we state 'political nature and power,' we are not referring to political party affiliation but the political nature of choice. For example, although EBs are capable problem solvers, teachers may give EBs simple calculation tasks because they think EBs cannot read the language embedded in math problems. As a result, EBs cannot learn rich mathematics and may never achieve their grade-level mathematics learning because they are never mathematically challenged. Task selection is a political act in that it exposes students to 
or from cognitively challenging mathematics and various real-world contexts, including critical issues surrounding EBs.

CSP is important as it provides a counter to what Valenzuela (1999) calls subtractive schooling, where the school becomes a space that erases student identities. If students cannot explore their own culture in the classroom, they will gradually disregard their cultural knowledge at school. It is common for EBs and immigrant students to live in two different worlds (school and home) with different identities. This is not their choice, but they do this because they know parts of their identities are not accepted or valued at school. One of the authors of this book, Martinez shared his story of how schooling affected his identity.

I know for myself, as early as the third grade, I associated speaking Spanish with being stupid because ELL[EB] students were placed in the same class as special education students. ${ }^{1}$ I stopped speaking Spanish first at school, then at home, and without practice my first language, my Spanish stopped developing. This was clearly not a CSP because the school helped to erase my language instead of supporting its development. Additionally, a divide between me and my mother started because she only knows Spanish. To this day, it is difficult to efficiently communicate with her and I just think of how many conversations and stories I missed having with her.

His story is not unique, with multiple individuals viewing Spanish (or other non-English languages) as a second or inferior language to English. Bucholtz, Casillas, and Lee (2017) explained how language, culture, and identity are deeply intertwined based on their research studies with over 800 public school students as follows.

That is, it is culture, produced primarily via language, that endows experience with meaning and provides a deeply held sense of identity and social belonging. It is precisely because of the central role of language and culture in sustaining selfhood that there is a vital need for pedagogical practices that sustain students' language and culture in classrooms and other learning contexts (p. 45).

This is where CSP shines once again because CSP specifically works to create spaces that foster linguistic and cultural openness by viewing students' cultural identities as assets to be incorporated into the classroom (Paris, 2012). When students' language and culture are valued and when students are respected as experts for their linguistic and cultural backgrounds, educators and students become co-learners and co-owners in learning and

1. I(Martinez) associated being an EB student as being the same as a special education student and because he, in the third grade, thought special education students were stupid, concluding that EBs were stupid too. This was wrong because special education students are not stupid and are capable of high levels of thinking, just like everyone else. 
teaching. In a CSP classroom, EBs can understand their language as creative and innovative rather than wrong or imperfect, "as a powerful symbol of family and community belonging rather than as a marginalized practice” (Bucholtz, Casillas, \& Lee, 2017, p. 55).

CSP is theoretically grounded in the two theories, Funds of Knowledge and Third Space. We will briefly discuss the two theories before focusing on the possible impact of CSP in the teaching and learning of EBs.

\section{Funds of Knowledge}

In the book Latinization of U.S. Schools (Irizarry \& Medina, 2015), high school student Jasmine Medina shared the following words:

I am sure that teachers have more complex identities than they share with students in school, and they seem to want us to be as one-dimensional as they seem to be. Many of my teachers want to put labels on me and fit me into nice, neat categories that allow them not to think too much of who I am and what I can be, just where I belong - or where they think I belong (p. 57).

Now, we would like to ask you the following two questions:

1. As a teacher (or future teacher), how did Jasmine's quote make you think and feel, and how does that relate to your classroom?

2. How does Jasmine's quote relate to Civil (2014), the quote used at the start of the chapter?

We ask you these questions to highlight the fact that students already have a unique and multi-layered identity when they walk into your classroom. At the same time, your classroom is a space where they will continue to develop their identities, which will interact with your own multi-layered identity. The concept of funds of knowledge refers to "the historically accumulated and culturally developed bodies of knowledge and skills essential for household or individual functioning and well-being” (González et al., 2006, p.133). As teachers, we can make a choice of identifying students' funds of knowledge or ignoring them. Choosing to ignore students' funds of knowledge may make it difficult for teachers to look past stereotypes that they may have of their students. We can see this in the words of Jasmine, where she later stated, "Students, who are given labels like English learners or Special Ed students, are constructed as problems and stereotypes about these groups shape how teachers think about us and the approaches they use to teach us” (Irizarry \& Medina, 2015, p.58).

After acknowledging and cultivating students' funds of knowledge, the challenge of incorporating them into the classroom becomes apparent. In mathematics education, much 
work has been done in cultivating funds of knowledge by the Teachers Empowered to Advance Change in Mathematics (TEACH Math) Project that "focuses on integrating children's mathematics thinking and children's home and community-based funds of knowledge in mathematics methods courses" (Drake et al., 2015). In this project, researchers explore how mathematics lessons can incorporate students' funds of knowledge into classrooms, which is a core principle of CSP and culturally relevant pedagogy in that it honors students' culture. In the case of emergent and experienced/ proficient bilinguals, incorporating students' funds of knowledge also honors student's language(s). Click on the image below to explore the TEACH Math Project.

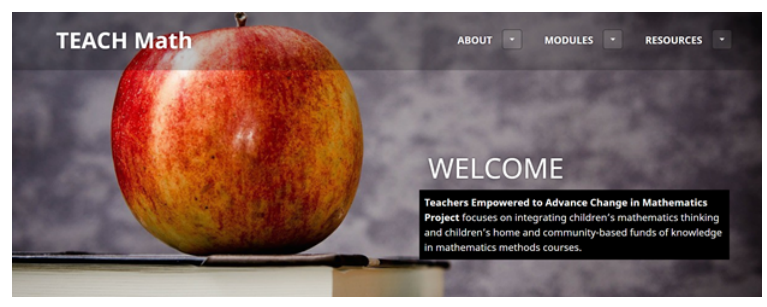

Here we want to add a discussion for backlash or pushback. From our previous experience working with teachers, we found many teachers were afraid of asking EBs to share their home culture in class because the teachers assumed that EBs might not be comfortable sharing their home culture (i.e. funds of knowledge). We have dissected these likely occurring thoughts into various scenarios and attempt to propose some teacher actions that we believe are suitable for the CSP framework.

Case 1: Teachers believe that EBs have an embarrassing culture and history.

This is the worst scenario, and we hope this is not happening in real classrooms. These teachers have deficit views of EBs' backgrounds and see EB's home culture as inferior to the mainstream culture in the US.

Case 2: Teachers believe all cultures should be valued but are concerned that EBs may feel embarrassed by their culture.

These teachers still have a deficit view on EBs. Most EBs are proud of their identities and cultures. I remember how enthusiastic the EBs in our projects were when they shared their life and cultural experiences. If EBs feel uncomfortable with sharing their culture, it is probably not because they are embarrassed by their culture but because they have other reasons, which are described in Case 3. If some EBs really think their culture is inferior to that of the US, it is a red flag because it is likely due to the continuous negative message about their culture from society. How can they live well with the deficit view on their own 
culture and identities? In this case, teachers must actively intervene to change the deficit views. This could also be a red flag indicating that the school's culture does not embrace diverse home cultures (please see Case 3).

Case 3: Teachers believe it is great to share students' home culture in class and EBs value their home culture, but EBs refuse to share their home culture because they do not feel safe in the classroom or school, or do not want to be divided from the rest of students.

This tends to be the most frequent situation. EBs in upper grades are likely to know there might be people in their classes who would possibly bully them just because they are different from other students. They also know that by sharing their culture they could be the target of ridicule or disadvantaged in their social life at school. This is sad but a reality. If a teacher thinks, "I will ask EBs to share their home culture, but if they don't want to do that, there's nothing I can do," this does not help improve the situation and continuously leaves the EBs in an unsafe environment. The teacher's active involvement is required in this case which may involve working with the principal and other school leaders to incorporate valuing various home cultures as part of the school's mission and vision, and building a safe environment should be prior to asking EBs to share their funds of knowledge.

Our first suggestion is being proactive. A classroom you successfully build on CSP will ideally provide a safe space to all students, but it will not be built in a day. Our second suggestion is not giving up after your attempts are unsuccessful or if you receive pushback, resistance, or complaints from parents or students. As you know, silence or avoidance of addressing diversity and culturally sustaining environment does not save EBs but leaves them living in deficit views from others and themselves. Rather than avoiding difficult topics, we need to learn how to promote CSP within schools and prepare for responding to possible resistance.

\section{Third Space}

Third Space is a "hybrid space [that] is created when classroom members bring together elements of school culture and home culture to create something new" (Carlone \& Johnson, 2012, p. 155). In this definition, a school where only English is used is a first space, and home, where students use their first language dominantly, is a second space. Subsequently, a third space can be created by combining and interacting with both spaces, an intertwining space that results in something new and that includes all elements of both spaces. A classroom culture built on Third Space principles allows creative exploration from students using funds of knowledge from the student's home culture (González et al., 2006). Jobe and Coles-Ritchie (2016) applied the concept of Third Space theory to teaching 
EBs and stated, "If ELs [EBs] can create third space and White students [non-EBs] can learn to engage within the space without dominance, that is effective for both the ELs [EBs] learning and the overall social experience of all students in the classrooms" (Jobe \& ColesRitchie, 2016, p. 11). This statement explicitly describes the nature of Third Space and does not exclude anyone, but in fact values all students' learning through their own experiences.

In education, Third Space can be viewed as an extension of Vygotsky's Zone of Proximal Development (ZPD) in focusing on how learning is mediated and constructed in a learner's cognitive activity, which is influenced/supported by a knowledge holder. Third space is a collective space embracing the multiplicity of individuals and the various pedagogical practices that facilitate learning, where it "includes not only what students learn in formal learning environments such as schools, but also what they learn by participating in a range of practices outside of school" (Gutiérrez, 2008, p.149). This concept extends the ZPD outside of the classroom by connecting the knowledge co-constructed between student and parent(s) with the knowledge being gained between student and teacher. Rich mathematical learning spaces for EBs are ripe for being a Third Space when we honor EBs' abilities and provide them with challenging mathematical tasks connected to their home culture.

\section{NEPANTLA TEACHERS COMMUNITY}

Social Justice Mathematics Educators

An example of a Third Space for math teachers can be seen within Nepantla Teachers, where teachers have created a space for their own learning that embraces the multiplicity of teaching with their own identities in connecting teachers digitally.

To listen to a Podcast about Nepantla Teachers, click on the image below.

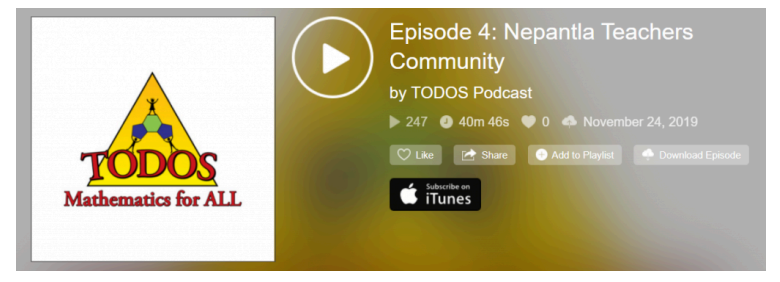

Outside of the classroom, mathematics as a Third Space can also be seen in the Algebra Project. 


\title{
Implementing Culturally Sustaining Pedagogy in Mathematics Education for EBs
}

\author{
Every day in America, children are still required to "leave" home, albeit symbolically, \\ because of the culturally chauvinist curriculum to which they are routinely \\ subjected, and most typically by teachers and school systems that systematically fail \\ to construct a meaningful educational practice out of students' languages, cultures, \\ community-based identities, or real-world experiences (Valenzuela, 2016, p. 8).
}

CSP begins when we bring our students' funds of knowledge to create a Third Space with the intent of transforming society. Mathematics classrooms should be part of a Third Space where students' funds of knowledge can take place. The reality at many schools, however, is that EBs are given simple rote-based mathematics tasks such as computation worksheets even when they are capable of doing high-level tasks such as problem-solving. Language can be a barrier for EBs (and all students), but it can also be an asset and instructional tool when teachers use it based on CSP in a Third Space. Creating language objectives, introduced in Chapter 1, is one example of supporting EBs. To ensure students opportunities to read, write, listen and speak about mathematics in the classroom, teachers are encouraged to consider students' rich language capabilities in both English and their first language(s) and to help them reach mathematics objectives by setting language objectives.

As mentioned by Moschkovich (2010), we need to treat EBs' home language as a resource for learning, to be shared with the class, instead of viewing it as a deficit that should be hidden away. CSP in the mathematics classroom acknowledges students' language and culture as an asset for learning and being a valuable classroom member. We will see more strategies and approaches for teaching mathematics to EBs based on CSP in the coming chapters.

The political nature of teacher task selection within a framing of CSP showcases how mathematical learning can be a rich, empowering process in two ways. First, CSP counters the image of EBs being second-class citizens and second-rate mathematicians. When EBs are only given simple tasks, it reaffirms that they are not smart and incapable of doing mathematics. Second, when EBs do not see themselves or their culture in the context of the problem, it makes them not want to share their culture in the classroom. It is important for students to share their language and culture because it normalizes their culture where they are no longer afraid to share with the class.

As we mentioned above, teachers may want to avoid asking EBs to share their culture and language in class because they thought EBs were not willing to do it. It is not because they feel embarrassed to show their culture, but because they do not feel safe to share their differences in the class. A safe space (Third Space) should be established before inviting EBs to share their assets, identities, and cultures. CSP also allows for students to continue 
to develop and learn about their cultural history without shame at school. Therein lies the power of all teachers in creating a CSP classroom where mathematics can allow for rich cultural experiences for all students. The power of teaching mathematics through CSP is that it seeks to empower students by allowing them to better understand the true nature of the world.

The reality and empowerment of EBs do not live in a vacuum, nor do funds of knowledge, and for this reason we must discuss the role of the community in creating a Third Space of mathematical learning for EBs. What are we doing to encourage community engagement in mathematical learning? Why is it particularly vital for EBs? Work in connecting mathematics to the community can be seen in Bridging funds of distributed knowledge: Creating zones of practices in mathematics (Gonzales et al., 2001) and the CEMELA project. Connecting community to classrooms is vital for EBs in order for them to feel safe and welcomed in school. Schools historically have not been friendly places for non-English speaking students. CSP seeks to dismantle language discrimination by celebrating all languages within the school and community. It is impossible to say you are empowering a student if that empowerment is confined to the walls of the classroom. Hence, students and community are intrinsically connected, as CSP works for the betterment of both.

Here lie the possibilities of CSP for/with EBs;

- where CSP views EBs as capable mathematics learners;

- where CSP provides realistic support for EBs to engage in mathematics;

- where CSP harbors rich, high cognitively demanding tasks for EBs to better understand the world;

- where CSP connects a classroom to the knowledge found at home (funds of knowledge), to then connect mathematics to the community;

- where mathematics allows CSP to be a third space, dancing between the parallels of language and mathematics;

- where CSP empowers teachers because at the heart of CSP is the joy of teaching;

- where CSP allows for students to sustain and further develop their own culture and language; and

- it is CSP within mathematics that provides a path for EBs to be seen as intellectuals.

The multiple approaches of CSP is a reminder that each of us reading this can create a safe and revolutionary mathematical learning space for EBs. Think about Jasmine's quote from earlier and how it applies to how teachers allow their students to see them. What would it look like if we allowed students to bring their whole identity(ies) into the classroom and took away the notion of identity in relation to categories and labels? Undoubtedly, CSP will look different in each classroom because each teacher is different and so are their students. Throughout this book, we will discuss various strategies that can aid teachers on their journey, but it is teacher's commitment to EBs and teaching mathematics that will transform lives. 


\section{CRMT Lesson Analysis Tool}

Rooted in culturally relevant teaching, the culturally relevant mathematics teaching (CRMT-TM) lesson analysis tool was created in order to help teachers reflect on their own teaching. The CRMT-TM tool specifically looks to promote intentional teaching discussions and critical reflection on mathematics lessons while centering mathematical thinking and equity. The tool was not created to evaluate a teacher or a teacher's ability. The main goal is to provide teachers with a framework to reflect on their own teaching and to help improve lesson design and implementation for all students, including EBs. The CRMT-TM lesson analysis tool focuses on six domains, each with a reflection prompt (TEACH MATH, 2012) as described in Table 2.1.

Table 2.1 Six Domains of CRMT-TM Lesson Analysis Tool

\begin{tabular}{|c|c|}
\hline Domain & Guiding Question \\
\hline $\begin{array}{l}\text { Cognitive } \\
\text { Demand }\end{array}$ & $\begin{array}{l}\text { How does my lesson enable students to closely explore and analyze math } \\
\text { concept(s), procedure(s) and reasoning strategies? }\end{array}$ \\
\hline $\begin{array}{l}\text { Depth of } \\
\text { Knowledge \& } \\
\text { Student } \\
\text { Understanding }\end{array}$ & How does my lesson make student thinking/understanding visible and deep? \\
\hline $\begin{array}{l}\text { Mathematical } \\
\text { Discourse }\end{array}$ & $\begin{array}{l}\text { How does my lesson create opportunities to discuss mathematics in } \\
\text { meaningful and rigorous ways (e.g. debate math ideas/solution strategies, use } \\
\text { math terminology, develop explanations, communicate reasoning, and/or } \\
\text { make generalization)? }\end{array}$ \\
\hline $\begin{array}{l}\text { Power and } \\
\text { Participation }\end{array}$ & $\begin{array}{l}\text { How does my lesion distribute math knowledge authority, value student math } \\
\text { contributions, and address status differences among students? }\end{array}$ \\
\hline $\begin{array}{l}\text { Academic } \\
\text { Language } \\
\text { Support for EB }\end{array}$ & How does my lesson provide academic language support for EBs? \\
\hline $\begin{array}{l}\text { Cultural/ } \\
\text { Community-based } \\
\text { funds of } \\
\text { knowledge }\end{array}$ & $\begin{array}{l}\text { How does my lesson help students connect mathematics with relevant/ } \\
\text { authentic situations in their lives? And how does my lesson support students' } \\
\text { use of mathematics to understand, critique, and change important equity or } \\
\text { social justice issues in their lives? }\end{array}$ \\
\hline
\end{tabular}

For your reference, view the full CRMT-TM Tool.

Within the tool, we can see how important recognizing students' contributions are in a mathematics classroom. Talk time and contributions should be distributed between the teacher, students, and among students. It would be helpful to audio/video record your own class, noting the length of teacher talk time and students talk time, as well as which students (or student groups) have more opportunities to speak or make contributions in mathematical discussions. Based on your reflection with CRMT-TM Tool, you can find effective ways to improve your teaching in terms of CSP and supporting EBs. 
1. How can mathematics classrooms create a space of empowerment for EBs?

2. What ideas do you have to first identify to utilize students' Funds of Knowledge? What are some of your own Funds of Knowledge?

3. What are additional ways to connect your classroom to parents and the community?

4. What are potential barriers that you foresee teachers encountering in implementing a Culturally Sustaining Pedagogy in their mathematics classroom? How can teachers work through those set backs?

\section{References}

Alim, H. S., \& Paris, D. (2017). What is culturally sustaining pedagogy and why does it matter? In D. Paris \& H. S. Alim (Eds.), Culturally sustaining pedagogies: Teaching and learning for justice in a changing world (pp. 1-21). Teachers College Press.

Bucholtz, M., Casillas, D. I., \& Lee, J. S. (2017). Language and culture as sustenance. In D. Paris \& H. S. Alim (Eds.), Culturally sustaining pedagogies: Teaching and learning for justice in a changing world (pp. 43-59). Teachers College Press.

Carlone, H., \& Johnson, A. (2012). Unpacking "culture” in cultural studies of science education: cultural difference versus cultural production. Ethnography and Education, 7(2), 151-173.

Civil, M. (2014). Why Should Mathematics Educators Learn from and about Latina/o Students' In-School and Out-of-School Experiences?.Journal of Urban Mathematics Education, 7(2), 9-20.

Irizarry, J \& Medina, J. (2015). How Can You Teach Us If You Don’t Really Know Us? Rethinking Resistance in the Classroom. In Latinization of US Schools (pp. 57-68). Routledge.

Drake, C., Aguirre, J. M., Bartell, T. G., Foote, M. Q., Roth McDuffie, A., \& Turner, E. E. (2015). TeachMath Learning Modules for K-8 Mathematics Methods Courses. Teachers Empowered to Advance Change in Mathematics Project. Retrieved from www.teachmath.info

González, N., Andrade, R., Civil, M., \& Moll, L. (2001). Bridging funds of distributed 
knowledge: Creating zones of practices in mathematics. Journal of Education for students placed at risk, 6(1-2), 115-132.

González, N., Moll, L. C., \& Amanti, C. (Eds.). (2006). Funds of knowledge: Theorizing practices in households, communities, and classrooms. Routledge.

Gutiérrez, K. D. (2008). Developing a sociocritical literacy in the third space. Reading research quarterly, 43(2), 148-164.

Jobe, J. \& Coles-Ritchie, M. (Ph.D.) (2016) Creating Third Space through Critical Interactions in a High School: Examining Latin@ Students' Experiences in Neocolonial Society, NABE Journal of Research and Practice, 7(1), 142-185. https://doi.org/10.1080/ $\underline{26390043.2016 .12067807}$

Ladson-Billings, G. (1995). Toward a Theory of Culturally Relevant Pedagogy. American Educational Research Journal, 32(3), 465-491. https://doi.org/10.2307/1163320

Moschkovich, J. N. (2010). Language and mathematics education: Multiple perspectives and directions for research. Information Age Pub.

Paris, D. (2012). Culturally sustaining pedagogy: A needed change in stance, terminology, and practice. Educational researcher, 41(3), 93-97.

Valenzuela, A. (1999). Subtractive schooling: Issues of caring in education of US-Mexican youth. State University of New York Press.

Valenzuela, A. (Ed.). (2016). Growing critically conscious teachers: A social justice curriculum for educators of Latino/a youth. Teachers College Press. 


\title{
3. EB-focused Strategies and Challenging Tasks
}

\author{
JI-YEONG I AND RICARDO MARTINEZ
}

\section{BUMBLEBEE Pre-Reading Questions}

1. What teaching strategies have you used (or heard of) for teaching mathematics to EBs? If you have used a strategy, how did it go?

2. Which strategies do you think work best for teaching EBs mathematics? Do you think a strategy that worked for some EBs will work for others?

Here are some different scenarios from various classrooms. Read each scenario, and think about what strategy you would want to implement for each context.

An interactive H5P element has been excluded from this version of the text. You can view it online here:

https://iastate.pressbooks.pub/teachingmath/?p=64\#h5p-10

You may notice we can make hundreds and thousands of different class scenarios like this. Even if you have EBs who speak the same first language or are from the same culture, the class they are in is an important factor in deciding how you will provide support for your EBs. We expect you came up with different strategies for each scenario, although some strategies may have been used more than once. If you have a specific math concept that you target for each class, you could probably find more specific strategies for teaching EBs. So, the math concept you teach also matters when developing an effective strategy for EBs.

\section{Let's recall an idea from the previous chapters.}

In the Introduction, you read that EBs are not a homogeneous group. For this reason, your strategy will change depending on which EBs you have and in what class setting.

Here are more things you may need to consider when developing or choosing good strategies for EBs. 
- What math concept will you teach?

- If the targeted math lesson is for conceptual understanding or procedural understanding...

- If the lesson involves abstract terms...

- If the lesson includes visuals like statistical graphs/charts, or geometric figures...

- Also, what skills or knowledge do you have?

- Can you speak the students' native language?

- Are you familiar with teaching English either as a first language (Language/ Communication Arts) or a second language?

- Are you confident in the specific math concept, so you can bring up many real-life examples?

\section{Let's recall another idea.}

In the Introduction, you saw that not all supports are the same. Not all visuals are the same. Read this word problem and find a visual that provides more access to the math for EBs.

Problem: The distance from where I am to the magic school cafeteria is $6 \mathrm{~km}$. My magic broom flies $2 / 3 \mathrm{~km}$ per minute. How many minutes will it take to get to the school cafeteria?

You will see two different visuals in the next slides. Think about which one would better support EBs. Ready? Click "next”

Visual 1:

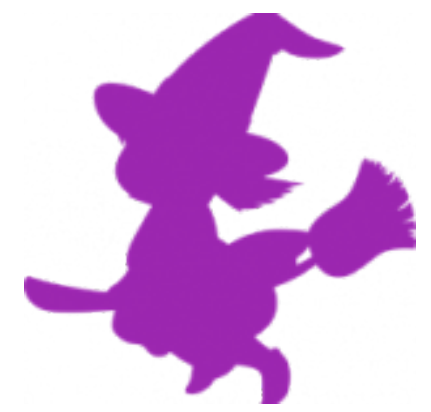

Visual 2: 


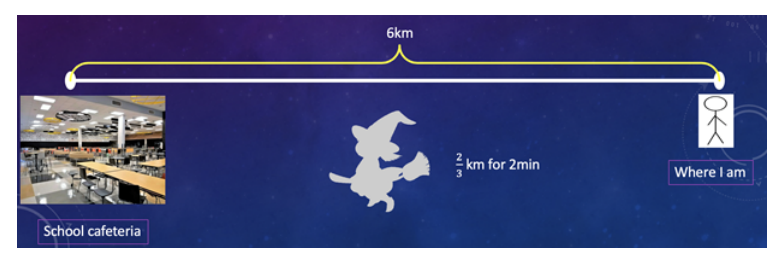

Which visual do you think will help give EBs better access to the math problem?

Why?

\section{Let's recall one more thing.}

In the previous chapter, we learned about CSP, culturally sustaining pedagogy, and how important it is to have high expectations for all students and support them to sustain the culture and language they already have. You can see how a recommended strategy for EBs follows this pedagogical guidance in the second chapter of the book, Beyond Good Teaching (Celedon-Pattichis \& Ramirez 2012). The authors provide guiding principles for teaching mathematics to EBs by considering the Common Core State Standards for Mathematics (National Governors Association Center for Best Practices \& Council of Chief State School Officers, 2010) and the Process Standards of National Council of Teachers of Mathematics (NCTM, 2000).

1. Challenging mathematical tasks

2. Linguistically sensitive social environment

3. Support for learning English while learning mathematics

4. Mathematical tools and modeling as resources

5. Cultural and linguistic differences as intellectual resources

The first principle, Challenging mathematical tasks, applies to all EBs at any level of English language development. The recommendation is clear: do not reduce the cognitive demand no matter what English level they are at, and no matter what mathematics level they are at. They deserve to receive an opportunity to learn rigorous mathematics with rich language activities. There should be high expectations for all students all the time. 
- Do not reduce the cognitive demand,

- Do not remove a challenging aspect from a math problem, but

- Make the problem more accessible by...

- Including students' familiar contexts and

- Providing appropriate support.

\section{Act Task}

As an example of challenging problems that integrate real-world contexts students are familiar with, we will introduce the 3 Act Task.

Dan Meyer, a thought leader in mathematics education, first developed and suggested using the 3 Act Task on his blog, dy/dan, and explained that students learn best in situations, "where students experience the world in concrete form, without the information that word problems typically provide, without sufficient resources to calculate.”

Just like the real-world problems we experience in our daily lives, a 3 Act Task does not include all the necessary information while textbook word problems do. Instead, the solvers of a 3 Act Task are supposed to identify what they need to solve the task and look for this information. This increases students' cognitive demand, engagement, and ownership of knowledge. Let's explore one example of the 3 Act Task.

An interactive H5P element has been excluded from this version of the text. You can view it online here: https://iastate.pressbooks.pub/teachingmath/?p=64\#h5p-11

This is the 3 Act Task. This strategy in itself may be already great for EBs and non-EBs, but if we further developed this concept into a 5 Act Task specifically for EBs we may be able to further support EBs language and mathematical development. 


\section{${ }_{5}$ Act Task}

For developing the 5 Act Task framework, we have added two new acts to the 3 Act Task: Act 0 and Act 4. Figure 3.1 shows the full cycle of the 5 Act Task framework. It is important to note that the five acts are not linear but iterative, meaning solvers can go back to any previous act as needed.

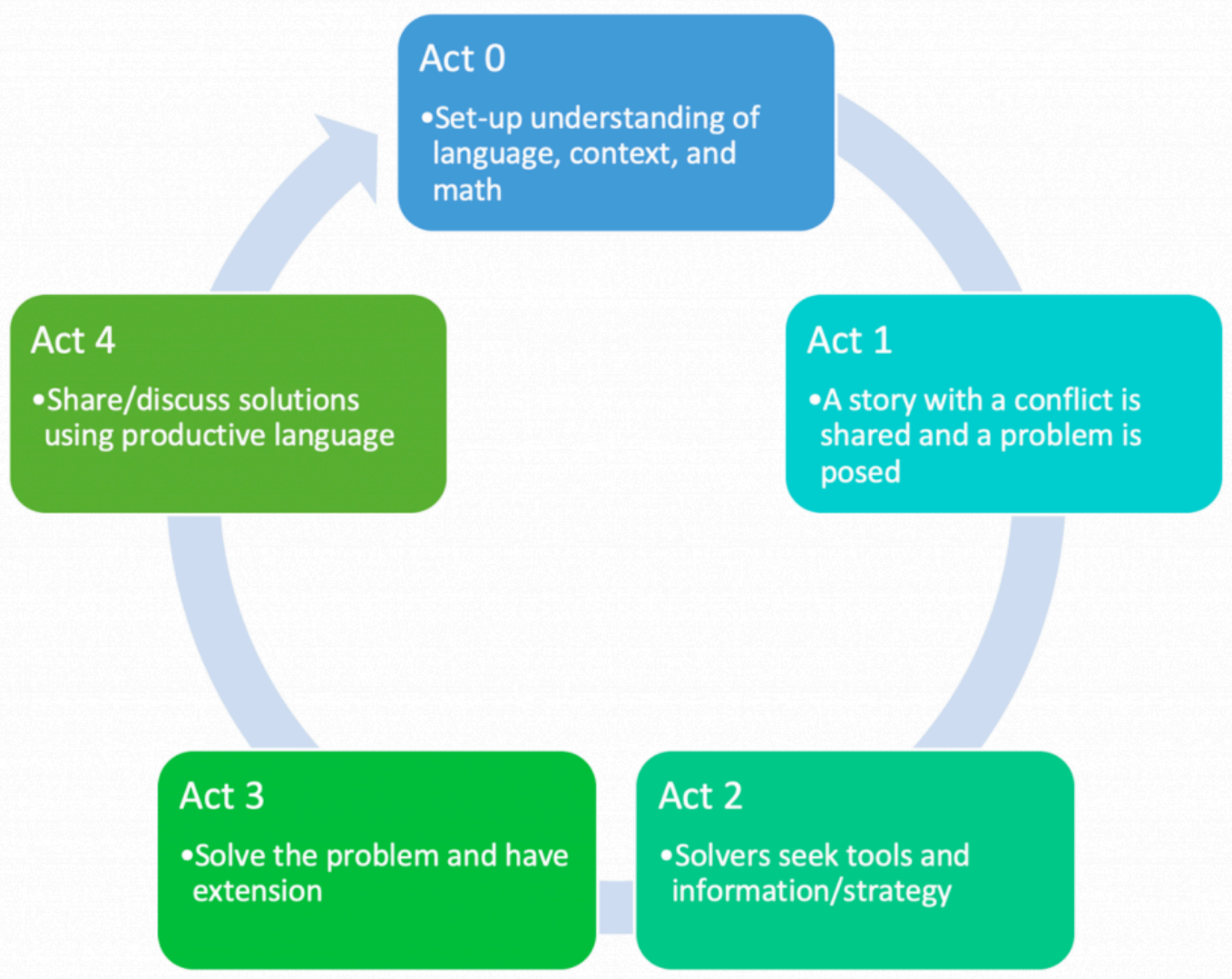

Figure 3.1 The iterative structure of the 5 Act Task Framework

Act 0 is the most crucial step because it reflects a set-up stage where teachers support EBs' understanding of both the language and the mathematics to be embedded in Act 1 . For example, a teacher assesses EBs' prior knowledge as it relates to the story (e.g., ask "Do you know how big a penny is?" or "What is a pyramid?”) and provides appropriate scaffolding (e.g., show a penny or have students build a small pyramid with pennies). Act 0 benefits all students because it helps them better comprehend the problem's context, but it is essential for EBs because unknown vocabulary or cultural nuances may prevent them from finding mathematical entry points. 
Act 4 starts after students find their solutions when EBs communicate about their solutions and reasoning behind their models. Because Act 4 involves productive language modes (writing and speaking), it can be challenging for EBs but simultaneously can provide a crucial opportunity for them to develop their English proficiency. To reduce EBs' anxiety of speaking English and to maximize their learning, teachers should design Act 4 carefully by applying various strategies, such as: having group/pair presentations, allowing EBs to explain with visuals and gestures, giving enough time to prepare what to say in English, using a graphic organizer, and writing sentence frames on the board.

The following table shows the purpose of each act of the 5 Act Task Framework. Remember the five acts do not have to be linear or follow a sequence. Teachers can flexibly revisit any of the acts as necessary.

Table 3.1: 5 Act Task modified for engaging EBs in mathematical modeling

\begin{tabular}{|c|c|c|}
\hline & Description & Purpose \\
\hline Act 0 & $\begin{array}{l}\text { Assessing/scaffolding before Act } \\
1\end{array}$ & $\begin{array}{l}\text { To support EBs by providing background } \\
\text { knowledge of the problem's language, context, and } \\
\text { mathematics. }\end{array}$ \\
\hline Act 1 & $\begin{array}{l}\text { A story with conflict via } \\
\text { multimedia/visuals/physical } \\
\text { movements and } \\
\text { problem-posing based on the } \\
\text { story }\end{array}$ & $\begin{array}{l}\text { To engage EBs in a relevant, real-life story towards } \\
\text { an authentic understanding of the mathematical } \\
\text { situation and to empower EBs by having them pose } \\
\text { their own problem(s). }\end{array}$ \\
\hline Act 2 & $\begin{array}{l}\text { Student-driven collection of } \\
\text { information to solve the } \\
\text { problem they posed }\end{array}$ & $\begin{array}{l}\text { To give EBs the agency to reflect on the story and } \\
\text { develop their own assumptions to solve them. }\end{array}$ \\
\hline Act 3 & $\begin{array}{l}\text { Model construction with } \\
\text { solution(s) }\end{array}$ & $\begin{array}{l}\text { To provide EBs with an opportunity to visualize/ } \\
\text { model their mathematical process, to analyze and } \\
\text { improve their decisions in the real world. }\end{array}$ \\
\hline Act 4 & $\begin{array}{l}\text { Collective communication of } \\
\text { solutions/thinking process }\end{array}$ & $\begin{array}{l}\text { To support EBs as they develop English proficiency } \\
\text { while also building mathematical competency. }\end{array}$ \\
\hline
\end{tabular}

Now, why don't you google "3 Act Task?” You will see numerous resources and sample tasks on many websites. Some of them are already matched with Common Core State Standards for Mathematics, so it is convenient for teachers to implement them in their classes. Save them as your resources and properly revise them with our 5 Act Task for the EBs in your classrooms. 
1. How do you think you can figure out what context students are familiar with and what real-life situations might be engaging for them?

2. What do you think would be the most challenging part for teachers of EBs when teaching a 5 Act Task lesson?

3. You read that it is important to provide EBs with challenging math problems, however, your students may resist and complain that the problem is too difficult. How would you help them engage in solving challenging problems?

\section{References}

Celedon-Pattichis, S., \& Ramirez, N. G. (Eds.). (2012). Beyond good teaching: Advancing mathematics education for ELLs. National Council of Teachers of Mathematics.

National Council of Teachers of Mathematics. (2000). Principles and Standards for School Mathematics. National Council of Teachers of Mathematics.

National Governors Association Center for Best Practices, \& Council of Chief State School Officers. (2010). Common core state standards for mathematics. National Governors Association Center for Best Practices, Council of Chief State School Officers. Washington, D.C. 


\title{
4. Power \& Participation of Mathematical Discussion
}

\author{
RICARDO MARTINEZ AND JI-YEONG I
}

\section{BUMBLEBEE Pre-Reading Questions}

1. What power do you think students exercise when they are able to ask a question in class? Likewise, what power do you think is lost from not being able to ask a question?

2. Why do you think having mathematical discussions is important for all students and why do you think it is essential for EBs?

3. What is the teacher's role when EBs are engaged in mathematical discussions with their peers?

"We are striving for... equity in our classrooms and schools,

but often failing to genuinely interact with each other in ways that support this goal”

- Zacko-Smith \& Smith (2010)

Have you ever asked your students a question only to then be surrounded by silence? Or have you experienced this yourself as a student? We can give three seconds of wait time, which should be at least five seconds for EBs, yet even after 30 seconds go by we might still be met with silence. What do you think is going on? Is prolonged silence a positive part of the learning process? Or is prolonged silence a negative sign? It is impossible to tell what the silence means without knowing the context, so we will focus on dialogues happening during mathematical discussions. Of course, there is no one absolute way to have all of our students answer all of our questions instantly. In fact, as we will see, this is not even ideal.

What we can do is create a classroom that welcomes and encourages participation. A classroom built on culturally sustaining pedagogy (CSP) is one way to help foster productive communication between students or between students and the teacher. The former focuses on participation for EBs to engage in discussions, and the latter reflects on the power that you, as a teacher, have. Thus, we started this chapter with a quote from Zacko-Smith and 
Smith (2010) because the heart of equity appears in and through dialogue. At the same time, mathematical discussions allow students to have meaningful interactions with their peers in solving rich mathematical tasks. In this chapter, we will focus on the importance of having our students engage in mathematical discussions, and in the next chapter we will focus more on mathematical languages. This leads us to the question of how we can guide a discussion that advances student learning, which is briefly addressed by former NCTM President, Diane Briars.

Watch this 3 minute YouTube Discussions that Advance Mathematical Learning video below.

A YouTube element has been excluded from this version of the text. You can view it online here: https://iastate.pressbooks.pub/teachingmath/?p=68

In this video, Diane mentioned that providing sufficient time for discussion is important and recommended not asking students, "Who wants to share?" because your student's replies may not go along with the learning objectives. If we do not ask students to randomly share what they'd like to share, how should we initiate and continue a discussion with students? Sharing time is also part of your instruction time, so it should be carefully planned to maximize students' learning and participation. One way we can accomplish this goal is through the 5 Practices for Orchestrating Productive Mathematics Discussions.

\section{${ }_{5}$ Practices for Orchestrating Productive Mathematics Discussions}

Smith et al. (2008) provided five practices for orchestrating a productive mathematical discussion, which are:

1. anticipating

2. monitoring

3. selecting

4. sequencing

5. connecting

Specifically, for EBs, the first step, anticipating, is key for addressing language concerns before they engage in mathematical learning. Without anticipating what EBs will be doing, the rest of the steps will be difficult for teachers to help EBs engage in, similar to the role of Act 0 in the 5 Act Task. Some of you may be familiar with Illustrative Mathematics, a digital mathematics textbook. Illustrative Mathematics is a non-profit organization that provides guidance and support for improving mathematics education, which has a blog on the 5 Practices for Orchestrating Productive Mathematics Discussions, along with many 
other resources for teachers. Use this link to access the blog: The 5 Practices: Looking at Differentiation Through a New Lens .

When you think you understand the 5 Practices, use the following task, which is from nctm.org, to check your understanding of one of the practices, sequencing. Try to solve the problem by yourself first and then carefully monitor the students' progress. Then, decide the sequence for what you want each student to share while considering your objectives.

Problem (adapted from nctm.org): In the movie "Pay It Forward," a student, Trevor, comes up with the idea that he can change the world. He decides to do a good deed for three people and with the hope that each of these three people would do a good deed for three more people and so on. He believed that before long, there would be good things happening to billions of people. At stage 1 of the process, Trevor completes three good deeds.

1. How does the number of good deeds grow from stage to stage? Describe the pattern in a sentence.

2. How many good deeds would be completed at stage 5 ?

3. Describe a function that would model the Pay It Forward process at any stage.

Student groups' solutions:

An interactive H5P element has been excluded from this version of the text. You can view it online here:

https://iastate.pressbooks. pub/teachingmath/?p=68\#h5p-12

\section{Mathematics and Language}

Hierarchical modes of learning a language, where learning is a linear logical chain, is a classical view of language and mathematics, sequencing teaching language first and mathematics later (Gutiérrez et al., 2010). As teachers, we know that if we wait for students to master a language before we teach mathematics, then our students will fall behind their peers in mathematics. Take the example of being in a foreign language class and only learning the rules of a new language and not practicing speaking the language until you master the rules. Are you learning that language when you are only learning the rules? It makes more sense to learn the rules along with getting practice speaking the new language. This example is similar to mathematics and language in that when we practice both together, they build and support each other.

Yet, for students who are practicing English, answering their teacher's questions may not be enough. We need to ensure that students are practicing the target language by engaging in dialogue with each other. The best way to do this in mathematics classrooms is to learn both English and mathematics through mathematical discussions. As recommended by Moschkovich (2010), we need to consider language in multiple settings and pay attention to 
how language does and does not manifest itself when EBs are engaged in a mathematical discussion. As stated by Gutiérrez (2018), "powerful learning is oftentimes a communal endeavor, not an individual one” (p.142). With mathematical discussions, EBs will not only hear their teacher but will hear how other students communicate while being immersed in the language.

\section{Teacher Authority and Power}

When we say "teacher authority," we are talking about the balance between teachercentered and student-centered learning. At the same time, what is the teacher's role during a student-centered mathematical discussion? As teachers, it is our duty to actively listen to students, to ensure that EBs have an opportunity to participate in discussions. It could be as simple as reminding students that they can draw figures and make tables that can help EBs better communicate. Or reminding students that they are allowed to speak in any language they choose. At this point, teachers should also remember that they are listening to mathematical meaning-making and not correcting EBs' language and grammar use. Remember, comprehension of language and mathematics is continually built through dialogue because no one person can know everything.

Additionally, it is the teacher's role to ask meaningful questions that help students dive deeper into their mathematical discussion. Here is where the power of a teacher lies - if a teacher can examine a task and anticipate what is needed to encourage EBs to exchange of ideas during a mathematical discussion, then these ideas, whether they include drawing pictures or using tables, can be built into the discussion, allowing for deeper engagement and communication between all students. Encouraging EBs to draw pictures and use tables is helpful because they now have the means to help mediate their mathematical discussion with the teacher and other students.

Teachers may not realize that selecting a problem's context is powerful. For EBs, we need to make sure the problem's context is void of any cultural bias because the last thing we want is the problem to force EBs to shut down, disengaging them from learning. Teachers can change the context to remove any cultural bias or prepare to pre-teach any unfamiliar cultural aspects before students start solving the task. Furthermore, problems grounded in the real world that reflect the identities of our students may be more engaging and motivating for all students because using these contexts places value on students' realworld, not an artificial or ideal world.

Everything mentioned in this section highlights the political power of teachers. Once again, we do not mean political in terms of political party affiliations, what we are referring to is the actions and choices that teachers make that impact students. For example, choosing to incorporate EBs' home culture in the classroom is a political act in that by seeing their home culture in school, students may feel more comfortable in the classroom. Choosing not 
to incorporate EBs home culture in class is also a political act because the potential benefits of doing so are lost. Teachers are charged with educating students; thus, all teacher actions have political consequences.

\section{Mathematics and Multiple Interactions of Language Engagement (Math-MILE) Tool}

It is important for all students, especially for EBs, to have opportunities to speak, write, read, and listen in mathematics classes, with teachers providing appropriate linguistic support and encouragement. Many teachers think they should reduce the number of words and the amount of reading for EBs because of the language barriers and extra time needed. We have often heard this kind of saying, "This is EB-friendly because there are no words." No doubt that these teachers have good intentions, helping EBs. However, if EBs do not have any exposure and experience with the target language, how can they learn the new language? Here is Walqui and van Lier's (2010) advice:

\section{Amplify, don't Simplify}

Again, amplify, don't simplify. Our roles, as teachers, are not in controlling or removing students' learning opportunities because we assume what they can or cannot do. Rather, we create opportunities and conditions in which learners can develop greater autonomy over their own learning. Based on this belief, we developed the Mathematics and Multiple Interactions of Language Engagement (Math-MILE) Tool by adapting the Language Demand in Mathematics Lessons (LDML) tool (Aguirre \& Bunch, 2012).

The LDML tool is a lesson design tool that helps teachers plan, implement, and reflect on their mathematics lessons with five language demands: reading, writing, speaking, listening, and representing. It is important for teachers to note that students do not develop language in any modality in isolation. Hence, it is crucial to consider including both receptive (reading and listening) and productive (writing and speaking) practice, as well as literacy (reading and writing) and oral language (listening and speaking). Representations, such as graphs, figures, and diagrams, are particularly important in mathematics lessons because they help EBs express mathematical knowledge and expand EBs' opportunities to understand and engage in a mathematical discussion. Here we provide some sample instructional questions for teachers to consider when using this tool during lesson planning (adapted from Aguirre \& Bunch, 2012, p. 188.)

- Do one or two language demands dominate my lesson plan?

- What does this information tell me about how I can support my EB students?

40 | Power \& Participation 
- Are language demands in one of the modes absent from a specific interaction type or the entire lesson?

- If my lesson plan has no writing demands, how will the absence of writing affect my EBs' mathematics learning?

- Do my EB students have enough time to interact with me and other students, both EBs and non-EBs?

The LDML tool is a matrix of the five language demands and three phases of a lesson, but we modified the LDML tool by adding interaction types instead of the lesson phases and named the modified tool as Mathematics and Multiple Interactions of Language Engagement Tool (Math-MILE Tool). The following figure is the matrix of the Math-MILE Tool.

Table 4.1: Mathematics and Multiple Interactions of Language Engagement (Math-MILE) Tool

\begin{tabular}{|c|l|l|l|l|l|}
\hline Interaction Types & Reading & Writing & Speaking & Listening & Representing \\
\hline Individual work & & & & & \\
\hline $\begin{array}{c}\text { Between the } \\
\text { teacher and } \\
\text { student(s) }\end{array}$ & & & & & \\
\hline $\begin{array}{c}\text { Between } \\
\text { student(s) and } \\
\text { student }\end{array}$ & & & & & \\
\hline
\end{tabular}

Our rationale behind the inclusion of interaction types is that EBs need to experience various interactions through mathematical discussions of multiple language modalities. If an EB has only individual reading, writing, and representing, the learning that occurs will be limited. If a teacher is the only one interacting with an EB, the EB's social status in their peer group will be reduced and this will influence their learning and motivation to learn as well. Although EBs may need individual preparation time, sometimes, just like other students, they also need to increase their confidence by participating in multiple forms of interactions, such as pair work, small group discussion, and whole-group discussions.

\section{Recommendations}

Mathematical discussion creates a space in the classroom for EBs to empower themselves. Through active engagement within mathematical discussions, students can move beyond simply explaining mathematics, and instead, they can generalize mathematical concepts (Hunter, 2017). It is worth noting that if the context of the problem utilizes a student's 
identity and home culture, mathematical discussions can also create spaces of selfdiscovery. While EBs construct mathematical knowledge with their peers, they develop their identities as well. If EBs can see themselves as creators of mathematical knowledge, then they can imagine themselves as mathematicians and scientists later in life.

Chapter 4 BUMBLEBEE Post-Reading Questions

1. How can the 5 practices for orchestrating productive mathematical discussion further enhance EBs' meaningful participation?

2. What does it take to have EBs lead whole-class discussions and how is that different from small group discussions?

\section{References}

Aguirre, J. M., \& Bunch, G. C. (2012). What's language got to do with it? Identifying language demands in mathematics instruction for English language learners. In S. CeledonPattichis \& N. G. Ramirez (Eds.), Beyond good teaching: Advancing mathematics education for ELLs (pp. 183-194). National Council of Teachers of Mathematics.

Carr, J., Caroll, C., Cremer, S., Gale, M., \& Lagunoff, R. (2009). Making mathematics accessible to English learners: A guidebook for teachers. WestEd.

Gutiérrez, K. D., Sengupta-Irving, T., \& Dieckmann, J. (2010). Developing a mathematical vision. Language and mathematics education: Multiple perspectives and directions for research, 29-71.

Gutiérrez, R. (2018). Rehumanizing mathematics. Re-humanizing mathematics for Black, Indigenous, and Latinx students: Annual perspectives in mathematics education. Reston, VA: National Council of Teachers of Mathematics.

Hunter, R. (2017). Mathematical Discourse that Breaks Barriers and Creates Space for Marginalized Learners. BRILL.

Moschkovich, J. N. (Ed.). (2010). Language and mathematics education: Multiple perspectives and directions for research. IAP.

Stein, M. K., Engle, R. A., Smith, M. S., \& Hughes, E. K. (2008). Orchestrating productive

42 | Power \& Participation 
mathematical discussions: Five practices for helping teachers move beyond show and tell. Mathematical thinking and learning, 10(4), 313-340.

Walqui, A., \& Lier, L. van. (2010). Scaffolding the academic success of adolescent English language learners: A pedagogy of promise. WestEd.

Zacko-Smith, J. D., \& Smith, G. P. (2010). Recognizing and Utilizing Queer Pedagogy: A Call for Teacher Education to Reconsider the Knowledge Base on Sexual Orientation for Teacher Education Programs. Multicultural Education, 18(1), 2-9. 


\title{
5. Translanguaging \& Word Problems
}

\author{
JI-YEONG I AND RICARDO MARTINEZ
}

BUMBLEBEE Pre-Reading Questions

1. Have you observed EBs working on mathematical word problems? What were they doing to solve the problem?

2. Have you ever thought that certain mathematical tasks are not appropriate for EBs? If so, what type of task was it and why did you think it was not appropriate for EBs?

3. Have you seen your EBs talking in their home languages? What did you do or what would you do if EBs used their non-English language in class or during recess?

\section{The Dilemma with Word Problems}

Consider the following vignette:

Ms. A is a 6th-grade math teacher. When her personal learning community (PLC) looked ahead at the unit assessment set for her next math unit, she sighed because it was full of word problems. In Ms. Smith's 6th-grade math classes, she has about 30\% Emergent Bilinguals, and about half of them are recent immigrants whose English proficiency is at the lowest level. Ms. Smith found some EBs to be very capable of mathematics and had been working hard to receive a good grade in mathematics. However, she was worried about whether they could demonstrate their mathematics knowledge properly with these word problems, many of which included complex sentences and difficult nonmathematical words.

What do you think about this story? Have you had a similar experience? Do you think this is common?

We agree that Emergent Bilinguals (EBs) can do mathematics. But, many teachers are likely to believe that word problems are difficult for EBs. Why? It may be a pervasive belief among teachers that word problems are inappropriate for EBs, and EBs may not want to be assigned word problems because they may not understand the problem statement or have anxiety from reading heavy texts. The story of Ms. A was made up, but consider this real story below. 
In one of my previous studies, Dr. I worked with preservice mathematics teachers. I recruited promising teacher candidates, and they volunteered to prepare a math lesson and work with one middle school EB in a one-on-one setting. One of the EBs was in an 8th-grade algebra class and the teacher who paired up with this student (let's call her Ms. B) knew about this fact. The first task Ms. B provided was simple addition and subtraction worksheet, with tasks such as 9+11, which is aligned with 1st-grade mathematics standards according to the Common Core State Standards for Mathematics. The EB, who was in an early algebra class, did all computation tasks with high speed and accuracy and left her teacher bewildered. Later, I asked Ms. B why she prepared those easy tasks for this EB. Ms. B answered, "I knew she was in early algebra and she is capable, but I thought she may have difficulty doing mathematics due to language."

What do you think about this story? Do you agree with Ms. B? The idea that "EBs cannot do well in mathematics due to language barriers" is a common belief and this belief makes teachers worry about not only word problems but also any mathematical tasks. If a mathematics teacher has this belief, they may think to themselves, "These tasks look too difficult for EBs, so I'll assign them easier worksheets." Research has in fact indicated that this belief is not uncommon. In fact, Reeves (2006) found that content teachers, including secondary math teachers, typically believe it is not appropriate to provide word problems to EBs due to their lack of English proficiency. What then can be done about these beliefs?

\section{How to Make Word Problems Accessible to EBs}

We would like to suggest rethinking these beliefs as the diagram below suggests. Teachers may observe EBs struggle in understanding word problems because they cannot fully understand the language. However, providing easy tasks or textless problems is not the only solution we can derive from this observation.

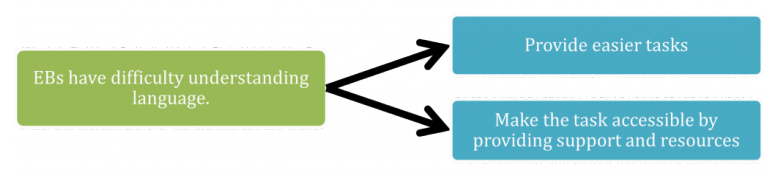


You identified that your EB students have difficulties reading word problems. What will you do to support them? Are you not going to give any word problems to EBs or give them only textless math tasks? Can you remove or reduce language demand without removing an opportunity to learn high-quality mathematics?

From here, we will talk about how we can make a word problem more accessible to EBs.

Generally, there are two directions.

First, we can reduce the language demand using following strategies:

1. Identify unnecessary parts and simplify the language

2. Provide more blank space on the worksheet, so students don't feel overwhelmed by heavy dense text, and so they will feel free to jot down their ideas in the space provided.

3. Break down the word problem statement into multiple steps.

We need to be careful though. When you reduce the language demand, you must not reduce the mathematical demand. Also, be careful not to reduce the language demand too much because your EBs need to learn language through rich and varied English texts.

Second, we can provide linguistic support:

1. Provide mathematically meaningful visuals: You have seen what kind of visuals work better in Chapter 3. Just adding a picture related to the story or context does not help EBs reason mathematically. To learn more about mathematically meaningful visuals for EBs, you can check out the following MTE article and Podcast.

- MTE article: I, J.-Y., \& Stanford, J. (2018). Preservice teachers' mathematical visual implementation for emergent bilinguals. Mathematics Teacher Educator, 7(1), 8-33. https://doi.org/DOI: 10.5951/mathteaceduc.7.1.0008

- Podcast at AMTE site

2. Have a set-up time before showing a word problem (I \& de Araujo, 2019): During the set-up, a teacher can assess students' understanding in relation to both mathematics and language to identify what needs to be taught beforehand. In addition, a teacher should assess students' prior knowledge about the context. For example, when we taught EBs who were from refugee families, we changed a mathematics problem's context from receiving a birthday gift to receiving an allowance because the EBs did not know their real birth dates and had never celebrated their birthday. If the result of this informal assessments indicates that you need to teach some words, cultural 
context, and/or prior math concepts, try to reteach or address this before you give the word problem so all students can be on the same page when they are given the word problem.

3. Utilize multimedia. The word problem does not always have to be in written form. For example, the story could be delivered through a video as you saw in the 3 Act Task and 5 Act Task introduced in Chapter 3. When you use multimedia that does not include any language, you can include other language activities such as discussion, presentation, or writing a journal to provide rich opportunities for EBs to develop their English skills.

4. Allow EBs to use their assets. Let EBs use their most comfortable communicative methods (e.g., written, verbal, drawing) to allow them to ask and respond to each other (if there are proficient bilinguals in the language of your EBs or if you have created a safe environment in your classroom). Most importantly, let EBs use their most comfortable language. Here, the concept of Translanguaging may help.

\section{Translanguaging}

[The content from here is adapted from Ofelia García's presentation in 2015]

What do you think translanguaging means? To explain what it means, let's start by reflecting on the following two short discourses:

Situation 1: Two 5-year-old Emergent Bilinguals who are speakers of Spanish in a bilingual classroom.

T: This tree is bigger. That tree is smaller.

Alicia: [Tries out under her breath]. This tree is grander.

Situation 2: Snack Time for a 5-year-old Emergent Bilingual.

Student A: [Looking out the window and talking to himself] Está lloviendo mucho. [It is raining a lot] Look [telling the others]. It's washing. There washing afuera [outside]

Question: What did you notice from the EBs' discourse?

In these dialogues, they used two languages in one sentence or in one situation.

What did you notice from the dialogue above? Did you notice the following?

- EBs are not simply adding English, but using a whole autonomous language with Spanish. 
- They are using their own language features in an interrelationship with new ones to make meaning and communicate.

- They are constructing their dynamic bilingual repertoire by adding features to those they already have.

The concept of code-switching, which describes how bilinguals perform discourse as they move from one language to another, is based on the belief that two separate languages exist in the brain of bilinguals. The term, code-switching has often been used negatively, indicating that bilinguals' use of two languages within a sentence represents imperfect language acquisition.

However, we see the discourse pattern of bilinguals in the examples above as translanguaging, which is a natural way of how bilinguals/multilinguals use their multiple languages with their one language system. We can see that the speakers are actually combining two (or more) languages to communicate as meaningfully as possible. If you find EBs using two languages in one sentence, it does not mean a lack of language acquisition. Rather, they use two languages in an intertwined manner to communicate in the most meaningful way possible at their level. Hence, it is not necessary for teachers (or parents) to push EBs to use only one language in a sentence. If we force them to use only one language, it denies their whole language system and rejects part of who they are and what they can do.

So, which way would you guide your Emergent Bilinguals?

$\rightarrow$ Utilize ONLY FEATURES THAT HAVE BEEN APPROVED BY SCHOOL for the task

$\rightarrow$ Utilize ANY OF THE FEATURES in their language repertoire to show what they know and can do.

Learners ALWAYS leverage their entire language repertoire in the process of communication. With an understanding of translanguaging, we can change the question, "How do I support students to learn English as a second language?" to "How do I engage students in appropriating the language features associated with English into their own unique language repertoire?”

\section{Translanguaging Pedagogy}

Translanguaging can support EBs in more than the two ways discussed above. Translanguaging approaches do not reduce language demand but provide a richer and safer language environment so that EBs do not feel overwhelmed by the language demand. By valuing and enacting translanguaging, teachers can value not only students' culture and language but also their identities as bilinguals (or multilinguals). This section includes

48 | Translanguaging 
how to employ a translanguaging pedagogy for teaching. Translanguaging Pedagogy means the deployment of a speaker's full linguistic repertoire to learn and develop ways of using language and extend their repertoire and to equalize the positions of learners. For EBs, a Translanguaging Pedagogy removes the handicap of English-only instruction that has been shown to harmful for EBs (Garcia, 2015; Fu, Hadjioannou, \& Zhou, 2019).

In the Foreword of the book, The Translanguaging Classroom: Leveraging Student Bilingualism for Learning (García, Johnson, \& Seltzer, 2017), Guadalupe Valdés, a researcher in bilingualism at Stanford University, noted that this book is "by far the most compelling example proposed to date of a culturally sustaining pedagogy" (p. vii) with the following explanation.

Too often, proposed pedagogies for cultural responsiveness or relevance have not necessarily invited students to value what they bring or to proudly continue to use features of their full linguistic repertoires in both formal and informal oral and written production for a variety of purposes in and out of school. This book [translanguaging] is different. It explicitly takes the position that past scholarship on language has misunderstood the nature of bilingualism and bilingual practices. It insists that students be invited to foster, maintain, and develop their complex repertoires. It invites teachers to reject static views of Language A versus Language B kept separate and pristine. It urges them to engage thoughtfully and joyfully with the richness of multicompetence in children's lives.

- Guadalupe Valdés within García, Johnson, \& Seltzer (2017, p. vii-viii)

Emphasizing that translanguaging is a pedagogical model grounded on pluralist theory, $\mathrm{Fu}$, Hadjioannou, and Zhou (2019) propose three key tenets for translanguaging practice that can be used in any setting with both emergent and experienced/proficient bilingual students.

1. Individuals have a single, unified linguistic repertoire.

2. Teachers are co-learners in their classrooms, willing to learn from students, their languages, and their cultures, rather than functioning as the sole possessors of knowledge, "the expert" or the only language instructor in the classroom.

3. Translanguaging practice is purposefully and systematically incorporated in both instructional planning and practices.

To help gain a better understanding of how to apply translanguaging pedagogy to a classroom, we will introduce a case of a 5th grade class, which was included in the book, Translanguaging for Emergent Bilinguals (Fu, Hadjioannou, \& Zhou, 2019). Mr. Miller is a 
native English speaker who learned Spanish as a foreign language and the students in the class speak English, Spanish, Polish, Arabic, and Russian. In the classroom, the learning objectives, class schedule, and homework assignments are written in five languages. There is also a word wall of the five languages that Mr. Miller asked students to create, so the students completed the word wall with help from parents and family members.

To prepare for the lesson, Mr. Miller asks the students to do research about school bullying using all of the assets they have including their family members, books and internet resources written in any language and to take notes in the language of student's choice.

During the lesson, students share their notes in groups in various forms, such as stories, blogs, or real experiences. The students switch back and forth between their home languages and English depending on their audience to make sure everyone understands the conversation.

Next, Mr. Miller reads a storybook on school bullying aloud in English and shows the pictures to the class without stopping the first time. During a second reading, he reads a section and then pauses, letting students talk to their neighbor and discuss what they have learned using any language they choose.

After this, Mr. Miller writes key words related to bullying in English on the board, and invites students to add different home language words under the English words. If they don't know the word in their home language, they can check the words online or in dictionaries. Phonemic spelling of the words using the Latin alphabet is acceptable.

After checking the key vocabulary words, Mr. Miller asks the students to write individually in any language on their thoughts about the book and any connections they might have between the story and their prior knowledge. After this quick-write, students have a group discussion using translanguaging. When the teacher comes to a group with a language he doesn't know, the students immediately shift their language to English so the teacher can understand them.

After the group discussion, each group creates a list of questions about bullying they want to investigate and presents them in class. Most questions are written in English, though some questions include words in other languages. Mr. Miller writes the questions on the board including significant non-English words in parentheses. The teacher and students go over the questions together and choose four questions they want to explore, and a new set of student groups discuss the questions.

Before the end of the class, the groups plan how they will find the information to respond to the chosen questions. Mr. Miller closes the class with this 
statement, "Your resources can be in any language you want, but please share your information tomorrow in English so we can all understand you.”

This is an example of a social studies translanguaging classroom, but you may find a way to apply similar strategies for math classes. Here are some examples of translanguaging strategies for mathematics teachers.

1. Give a word problem in English and give students time to discuss and write their solutions in their own languages (or vice versa).

2. Let students to see or listen for synonyms and homophones for certain words in English, their home language or both.

3. Give EBs an opportunity to demonstrate their knowledge and skills in mathematics in a variety of ways (multiple languages and multiple modes).

4. Encourage EBs to use various resources in their home languages including their family members.

You may want to see what a math lesson looks like when it employs a translanguaging pedagogy. You can find one example at the website of CUNY-NYS Initiative on Emergent Bilinguals (CUNY-NYSIEB, ).

\section{Word Problem Analysis Framework}

We say teachers need to make mathematical problems accessible to EBs, but what exactly does that mean? According to Luciana de Oliveira (2012), accessible in this statement means providing EBs with "access to the ways in which knowledge is constructed in the content areas-not by simplifying the texts, but by developing teachers' understanding about how mathematical disciplinary discourse is constructed (p. 195). This section introduces one accessible way to use word problems for EBs by applying the Translanguaging Pedagogy and Word Problem Analysis Framework (Oliveira, 2012).

Here is one example of a word problem:

Moises is saving money to buy a book, which costs $\$ 20$. He can save $\$ 3$ per week. How many weeks will it take him to save enough money to buy the book?

This word problem can be divided into three clauses:

Clause 1: Moises is saving money to buy a book, which costs $\$ 20$.

Clause 2: He can save $\$ 3$ per week.

Clause 3: How many weeks will it take him to save enough money to buy the book? 
de Oliveira (2012) recommends analyzing each "clause" of a mathematical word problem to identify the language demand needed to make the problem accessible for EBs. She proposed five questions based on Huang and Normandia (2008).

1. What task is the student asked to perform?

2. What relevant information is presented in the word problem?

3. What mathematical concepts are presented in the information?

4. What mathematical representations and procedures can students use to solve the problem, based on the information presented and the mathematical concepts identified?

5. What additional language demands exist in this problem?

The table below is a framework that can be used by teachers or students. Teachers are encouraged to fill out the form in advance, before asking students to analyze the given word problem. We adapted the Framework for Analyzing Word Problems (de Oliveira, 2012) by adding translanguaging components. 
Table 5.1: Translanguaging Framework of Analyzing Word Problems

\begin{tabular}{|c|c|c|c|}
\hline $\begin{array}{l}\text { Information Provided } \\
\text { in English }\end{array}$ & $\begin{array}{l}\text { Information in a } \\
\text { language of choice }\end{array}$ & $\begin{array}{l}\text { Mathematical concept } \\
\text { in a language of } \\
\text { choice }\end{array}$ & $\begin{array}{l}\text { Mathematical } \\
\text { Representation and } \\
\text { Procedures }\end{array}$ \\
\hline \multirow[t]{2}{*}{$\begin{array}{l}\text { Clause } 1 \text { : Moises is } \\
\text { saving money to buy } \\
\text { a book, which costs } \\
\$ 20 \text {. }\end{array}$} & \multirow[t]{2}{*}{$\begin{array}{l}\text { 모세는 } \$ 20 \text { 짜리 책을 사 } \\
\text { 기 위해 저금하고 있다. }\end{array}$} & \multirow[t]{2}{*}{$\begin{array}{l}\text { The cost of the book: } \\
\$ 20\end{array}$} & $=\$ 20$ \\
\hline & & & $\$ 20$ \\
\hline \multirow{4}{*}{$\begin{array}{l}\text { Clause } 2 \text { : He can save } \\
\$ 3 \text { per week. }\end{array}$} & \multirow{4}{*}{$\begin{array}{l}\text { 모세는 매주 3달러 모을 } \\
\text { 수 있다. }\end{array}$} & $\begin{array}{l}\text { Money that Moises } \\
\text { can save for } 1 \text { week: } \\
\$ 3\end{array}$ & Money from $1^{\text {st }}$ week \\
\hline & & \multirow[t]{2}{*}{ Per week: 1주 } & 모아야하는 돈 \\
\hline & & & $\$ 20$ \\
\hline & & $\begin{array}{l}\text { Therefore, } \$ 3 \text { can be } \\
\text { saved each week. }\end{array}$ & \\
\hline \multirow{4}{*}{$\begin{array}{l}\text { Clause } 3 \text { : How many } \\
\text { weeks will it take him } \\
\text { to save money to buy } \\
\text { the book? }\end{array}$} & \multirow{4}{*}{$\begin{array}{l}\text { 모세가 책을 살 수 있을 때 } \\
\text { 까지 몇 주나 걸릴까? }\end{array}$} & \multirow{4}{*}{$\begin{array}{l}\text { Money to buy the } \\
\text { book } \geq \$ 20 \\
\text { 모인 돈이 } \$ 20 \text { 보다 많아 } \\
\text { 야 한다. }\end{array}$} & $\begin{array}{l}\text { Money for } 6 \text { weeks } \rightarrow \text { still less than } \\
\$ 20 \rightarrow \text { need one more week }\end{array}$ \\
\hline & & & $\$ 3$ \\
\hline & & & Goal \\
\hline & & & $\$ 20$ \\
\hline
\end{tabular}

The goal of using this framework is to enable teachers to be more proactive in helping EBs learn the ways in which language is used to construct mathematical knowledge. Although this framework shows reading, writing and representation modes, teachers can utilize other language modes, such as speaking or gesturing in classrooms. The teachers should clearly provide directions for using this form so that students can use any language they choose, as this tool is for them to understand the language and mathematical information embedded in a word problem. Sometimes, teachers may give a word problem written in their EBs' first language and change the second column to translating each clause into English. In this way, EBs can develop not only English but also their first language, and by comparing the two languages, EBs can deepen their understanding of English. After students fill out this form, the teacher can ask students to share their analysis with their group. Students can start solving the problem after the teacher makes sure everyone understands the problem's language through this framework.

We would like to close this chapter with the following quote from de Oliveira (2012).

Content is never separate from the language through which that content 
manifests itself. Learning mathematics means learning the language that expresses mathematics. The language demands that this chapter addresses highlight the kind of discipline-specific academic support in language and literacy development that would enable English language learners to be more successful in their mathematics learning (p. 204).

\section{Reference}

de Oliveira, L. C. (2012). The language demands of word problems for English language learners. In S. Celedon-Pattichis \& N. G. Ramirez (Eds.), Beyond good teaching: Advancing mathematics education for ELLs (pp. 195-205). National Council of Teachers of Mathematics.

Fu, D., Hadjioannou, X., \& Zhou, X. (2019). Translanguaging for emergent bilinguals: Inclusive teaching in the linguistically diverse classroom (First edition). Teachers College Press.

García, O. (2015), The translanguaging current in language education, Presented at åhörarkopior från Symposium 2015. Retrieved from https://www.slideshare.net/ NCandrasprak/ofelia-garca-hrarkopior-frn-symposium-2015

García, O., Johnson, S. I., \& Seltzer, K. (2017). The translanguaging classroom: Leveraging student bilingualism for learning. Caslon.

Huang, J., \& Normandia, B. (2008). Comprehending and solving word problems in mathematics: Beyond key words. In Z. Fang \& M. Schleppegrell (Eds.), Reading in secondary content areas: A language-based pedagogy. University of Michigan Press.

I, J. Y., \& de Araujo, Z. (2019). An examination of monolingual preservice teachers' set-up of cognitively demanding mathematics tasks with emergent multilingual students. Research in Mathematics Education, 1-21. https://doi.org/10.1080/14794802.2019.1615980

I, J. Y., \& Stanford, J. (2018). Preservice teachers' mathematical visual implementation for emergent bilinguals. Mathematics Teacher Educator, 7(1), 8-33. https://doi.org/DOI: 10.5951/mathteaceduc.7.1.0008

Reeves, J. (2006). Secondary teacher attitudes toward including English-language learners in mainstream classrooms. The Journal of Educational Research, 99(3), 131-142. 


\title{
6. Connecting Learned Mathematics to Emergent Bilingual Families and Community
}

\author{
RICARDO MARTINEZ AND JI-YEONG I
}

\section{BUMBLEBEE Pre-Reading Questions}

1. What role do you think your students' parents play when it comes to students' mathematical learning? What role do you want the parents to have for your class?

2. What is a way a student's culture can contribute to their success in a mathematics classroom?

3. What community spaces outside of school contribute to your students' mathematical learning? How can we connect those spaces to the classroom?

"The ultimate goal for parental involvement in any partnership should be

to improve the quality of life in the community...

Parents who faithfully participated reciprocated the trust and respect

$$
\text { given to them and rose to the occasion." }
$$

(Lopez \& Donovan, 2009, p.220)

Have you thought about what roles parents had or have in creating a positive classroom learning environment? Students discussing mathematics at home means they are engaging with the content that they learned in class outside of the classroom. Students who extend their learning outside of the school have a positive effect on the classroom. In the outside world, parents or family members are probably the most important individuals and resources students have. Keeping this in mind, how can we, as teachers, communicate with parents to extend students' learning spaces? As mentioned in previous chapters, each household contains a wide breadth of knowledge. Thus, establishing a connection between 
the classroom and parents creates an ecosystem where mathematics can be learned for the betterment of the community.

All of us, as teachers, know that education provides a pathway for students to become anything they want to be, within the limits of reality. What many of us tend to overlook is that parents of Emergent Bilinguals (EBs) are there to support us because they tend to highly value education and are very supportive. Yes, there will be times when parents do not know how to be part of their child's learning but there are many instances where parents can help. If we view the second half of the previous quote by Lopez and Donovan, we see that parents can reciprocate the trust and respect given to them; if parents are not actively welcomed into school to get involved, then respect and trust can never be formed. If parents are not welcomed to the school, then it will be difficult for their students to feel welcomed as well. Have we ever asked ourselves how our school prevents parents from getting involved? Do we even know what our school does to engage parents outside of emails and sports events?

\section{Community Cultural Wealth}

In this chapter, we will focus on how the community where EBs live represents a wealth of support from its members. Specifically, we will explore Tera Yosso's Community Cultural Wealth Model (2005) in how it enriches culturally sustaining pedagogy and EBs. Before we get into community cultural wealth, watch the first five minutes of the video below to learn about social capital and cultural capital.

Pierre Bourdieu: Theory of Capital (Social and Cultural Capital)

A YouTube element has been excluded from this version of the text. You can view it online here: https://iastate.pressbooks.pub/teachingmath/?p=75

For EBs who are immigrants, refugees, or part of a historically marginalized group, they may not have the same social capital as the dominant group does. What they do have is cultural capital that comes from their family and ethnic/local community. The video talks about the difference between social capital and cultural capital, but we need to remember that social capital can be cultural wealth and cultural wealth can be social capital. Community Cultural Wealth is a model that acknowledges that culture does in fact influence how societies function and how people learn (Yosso, 2005). The meaning of wealth is different from income, which is money received from salaries, wages, or payments paid for services and products. We can define wealth as the total extension of an individual's accumulated assets and resources. Community cultural wealth takes an anti-deficit view. Yosso (2005) states, "Instead, community cultural wealth involves a commitment to conduct research, teach, and develop schools that serve a larger purpose 
of struggling toward social and racial justice (p. 82).” The six forms of community cultural wealth are as follows:

- Social Capital - refers to the networks of people and resources that people have available to them as they navigate the world.

- Navigational Capital - refers to the skills learned that help a person navigate social institutions. For example, an older sibling who has gone to college can help a younger sibling in understanding what it means to go to college, serving as a type of navigational capital.

- Aspirational Capital - refers to the perseverance in maintaining one's hope and dreams. For example, an older individual within the community who tells a child "to stay in school because you can do anything you set your sights on” would be aspiration capital.

- Linguistic Capital - refers to and "includes the intellectual and social skills attained through communication experiences in more than one language and/or style (Yosso, 2005, p. 78)" For example, translanguaging skills developed from bilingual home life is a form of linguistic capital.

- Resistance capital - refers to the skills learned through acts of resistance that marginalized people constantly live through. For example, a refugee family has experiences relocating from place to place. The perseverance learned from those experiences can be taught to other family members.

- Familial Capital - refers specifically to the cultural knowledge shared by a family and the history of and from the family. Funds of Knowledge EBs learn from their family is an example of familial capital.

The six types of capital are also not mutually exclusive as one person can represent multiple forms of capital. The example of a sibling who served as navigational capital could also simultaneously serve as familial capital and aspirational capital because the example was about college.

A focus on cultural capital helps in maintaining an asset-based view because it allows us to think beyond social capital alone (e.g., networking for jobs, etc.) and think of the many sources of wealth a person can have. Social capital can turn into a pathway to success, given some students have more social capital than others. For example, a person whose parents are both doctors will have more social capital than a person whose parents did not graduate from high school. If we consider or have only social capital, it may reinforce the discrimination inherited from the previous generation. What Community Cultural Wealth works to do is to diffuse the privilege some students have by acknowledging that all communities have multiple forms of capital that work in unison. 


\section{Implementing Community Cultural Wealth in School Settings}

Next, we will share three vignettes based on real accounts of EBs and their families' lives. We made slight modifications and intentionally hid identifiable information such as cultural backgrounds, nationalities, and names to highlight that EBs are not a single monolithic group and to help readers avoid any possible stereotypical views entangled with a specific group. After each vignette, we will ask for your perspectives as a teacher and discuss the role of and/or connection to community cultural wealth.

\section{Episode 1:}

Student A was born in the U.S. with both of her parents being non-native English-speaking immigrants. English is the most frequently spoken language for Student $A$ and she was never officially identified as ELL by her school or district. She does not know much about the language and culture of the country where her parents came from. One thing that stands out for Student $A$ is that she remembers her peers made fun of her when she brought traditional food to school eat. In general, she is not very comfortable when her teacher or peers ask about her language background or when they constantly ask "How do you say__ in your language?" She feels as though this kind of question separates her from her White peers in the predominantly White, monolingual school district.

\section{If you were a teacher of Student A, what would you do?}

In this vignette, the student's community cultural wealth does not make itself present in the classroom. Specifically, any linguistic capital the student may have is transformed into a nexus of shame by her peers' negative responses and her internal view, which is also probably initiated by external messages. If the classroom was a culturally sustaining classroom, however, students would welcome any cultural differences instead of making fun of a culture's food. Without restoring her cultural wealth, her classmates' questions and interest in her linguistic wealth still sound negative and embarrassing to Student A.

We, as teachers, should not assume all EBs positively identify their own capitals. Before they arrive in your classroom, they might have experienced many deficit views towards their Community Cultural Wealth. Helping them recognize and restore their capital and wealth is sometimes necessary prior to asking them to share their linguistic capital. Once again, here is where a translanguaging classroom would be beneficial. Consequently, we need to create a classroom that becomes their navigational and aspirational capital. When the classroom culture is positive and when the student knows that their culture and parents are welcomed and respected, they will then feel more comfortable speaking or sharing their language with you and the class.

Episode 2:

Parent $B$ is an immigrant and is a proficient bilingual although she is not a native English

58 | Families and Communities 
speaker. She was surprised when her son suddenly told her "Mom, you can speak English, so don't speak [your first language] when my friends are around. It's embarrassing." Parent $B$ was heartbroken and wondered where her son picked up that deficit view of their home language and any language for that matter. She was worried because what if her son's peers spoke negatively about his race, language, or culture. During the next parent-teacher conference, Parent B shared this concern with her son's teacher. The teacher, a middle-aged White woman, said she understood the concern and promised she would work on this in her class. A little later, when the class awards were being presented for the school's reading program, the teacher explicitly addressed bilingualism to all students in the class. The teacher said, "You know what? Being a champion of this reading program is great but speaking two languages is also a very wonderful thing. Student B [Parent B's son] can speak not only English but also another language. Isn't that great?”

1. What do you think about what the teacher of Student B did? If you were a teacher of Student B, what else would you have done?

This case is a good example of resistance capital in action, where Parent B took action to change an issue she saw in her child's life. Such a level of caring is at the heart of understanding familial capital because it is a myth that EBs' parents don't care about their children. In fact, research has shown that parents of EBs DO care about education and that is one of the reasons they came to the US. This is an example of what parent and teacher communication can do to extend Community Cultural Wealth, because now the teacher has become part of Student B's linguistic capital by seemly welcoming the student's home languages. It must be said that this is just the start. A teacher cannot create a positive classroom atmosphere or a culturally sustaining classroom by taking just one action. But, think about how Parent B will feel when their child comes home and tells her what the teacher said. This represents the beginning of a potential bridge between the classroom and the community.

\section{Episode 3:}

Students $C$ and $D$ are sisters and biracial. Their father is White, born in the United States and mother is non-white who immigrated from a non-English speaking country. Their family lives in a rural area with very little racial diversity, where it is common for them to be the only non-white students in the school. Their mother was worried that her daughters would lose their identities by not knowing both their languages and cultural heritages. The mother visited her daughters' teachers and shared her idea of a cultural day. The teachers liked her idea and scheduled a day for this event. On the cultural day, the mother prepared cultural food for all students in the classes, and students $C$ and $D$ prepared a presentation for each of their classes about half of their culture that is not normally seen in their school. It was a big success. The students in their classes loved the food and loved learning about another culture. Other students even gave positive comments like, "I'm so jealous of you! You can eat this delicious food every day!” 
1. What do you think about what the teachers of Student $C$ and Student $D$ did? If you were one of their teachers, what else would you have done?

In this episode, it appears like the teacher did not do anything when in fact the teacher took the chance in sharing their classroom space. If we, teachers, say no to parents about this kind of event because of concerns like time or any unexpected trouble, unintentionally we are creating barriers that keep parents away from the classroom. The highlight in this example is the presentation that came with the food. Having a cultural day where the only food is shared runs the risk of not really being about the deep-level of culture but more about an excuse to eat food; this can also lead to the development of stereotypes where people associate marginalized individuals solely based on food. By including the presentation, the food becomes a potential anchor to culture and the people who create that culture. If bringing food is not allowed by your school/district, you may use other cultural activities, such as teaching dance or a game (or even some of the language!). Community cultural wealth is a form of cultural capital that can find its way into any classroom and this episode is just one example.

It should be noted that the teachers in the episodes above were not trained with CSP or translanguaging. The teachers did not take any culturally sustaining actions for their EBs or bilingual students before the parents made suggestions. Still, it is important that they did gladly accept the parents' requests. If the teachers were equipped with CSP and translanguaging, the initiation of culturally sustaining actions would come from the teachers. On the first day of school, a teacher's statement of how cultural and linguistic diversity is respected and welcomed in the classroom would be made and displayed. A letter or syllabus that invites parents' funds of knowledge into the classroom community would be sent from the first day as well. Students would be allowed and encouraged to use any language(s) when they did classwork or homework. Bilingualism and multiculturalism would already be positively addressed before the parent in vignette two raised the issue and the bilingual student felt his parents were different from his peers' parents. We recommend teachers be proactive and explicitly share their teaching philosophy about multicultural and multilingual spaces so EBs and bilingual/multicultural students can feel safe in your classroom.

\section{View Parents as Intellectual Resources}

[This section is adapted from the webinar, Black, Indigenous, and Latinx Parents as Intellectual Resources: From Option to Imperative, by Civil and Zavala (2020)]

In this section, we focus on how teachers can involve parents in their teaching and for their students' learning in mathematics. First, let's consider the following statements.

Viewing parents as intellectual resources (Civil and Andrade 2003) is essential to

60 | Families and Communities 
establishing an authentic dialogue between Latino and Latina parents and schools. This means that schools are genuinely interested in parents' views and understandings of mathematics and that they want to explore ways for the school's mathematics instruction to reflect parents' knowledge and experiences.

(NCTM Research Brief, 2010)

...we envision a transformation in the role of nondominant parents and families from constrained and passive supporters in school-centric activities and agendas towards expert collaborators and fellow leaders in expanding disciplinary conceptions and reshaping teaching and learning across multiple contexts.

(Ishimaru, Barajas-López \& Bang, 2015, p. 14)

Both quotes emphasize that parents are reliable resources for education. During the COVID-19 pandemic, many teachers may be worried that parents cannot properly teach their children mathematics at home and the students will fall behind their grade level. Although teaching children at home requires a lot of work, we need to believe that parents not only know enough but they also know more than we think.

Imagine if parents of an EB taught their child how to solve an equation the way they learned in their home country. The EB used the method at school and the math teacher said, “Okay, but that's your mama's way. Let's do it the way that we do it in school." Now the EB knows that his school does math differently from what he does at home, so he will not ask his parents to help him with his mathematics anymore. This erases the student's familial capital and impacts how they see their parents. In a mathematics classroom where culturally sustaining pedagogy and Community Cultural Wealth are centered, the separation between school and home in learning mathematics does not happen.

Here are three examples of the kind of talk we might hear around a school that set up barriers to parent engagement.

- [On-site council, discussing parental needs]: "We need to help parents learn the math formulas they do not know so they can help their children at home."

- [During teacher meetings]: "The problem is that parents in this school are not involved."

- [During instruction, in response to a student sharing how her mom helped her solve a math problem]: "That's very cool that your mom showed you this way, but at school, we are going to do it the way we learned.”

How would you reframe the concerns in each example?

How would you, as a teacher, respond at the moment? 
Here we would like to share what research has found regarding parents' involvement in mathematics education. Math and Parent Partnerships with Schools is a program that helps children improve their mathematical learning by supporting their peers, families and schools. Their materials include Mathematics Workshops for families and Math for Parents Courses. You can find useful information and resources in both English and Spanish on the MAPPS website.

The MAPPS team has learned the following lessons by working with parents of diverse students, which they have successfully done since 1999.

- Latinx parents enjoy doing mathematics and want to learn about the mathematics their children are learning.

- Parents are effective facilitators of workshops for other parents. They know the community, they can easily connect with other parents can families, they can bring in a more natural way of interacting with others about mathematics.

- Parents, like everybody else, may have strong beliefs about what mathematics is and about the "right" way to do things.

- Parents are resourceful: they use their networks for support. For example, if English is an issue when completing homework, parents might ask neighbors for assistance.

\section{Conclusion}

Teaching can be isolating and is difficult when done alone. Connecting with parents allows for multiple possibilities to enrich the classroom. In Chapter 2, we talked about the potential and power of cultivating students' funds of knowledge when creating a culturally sustaining pedagogy in the classroom and followed up with a discussion of connecting EB families and communities to the classroom in this chapter. Speaking with parents provides an even easier approach to learning about the household knowledge and wealth of your students' families. Community cultural wealth shows us six avenues of capital that EBs have that can and should be welcomed inside the classroom. 
1. How can community cultural wealth be communicated to and for parents?

2. How can a math teacher represent the six types of capital within community cultural wealth?

3. What are the ways that you can make your classroom open and welcoming to immigrant and non-English speaking parents?

4. What role do assessments in mathematics classes play in highlighting community cultural wealth?

\section{References}

Civil, M. \& Menendez, J. (2010). Involving Latino and Latina parents in their children's mathematics education [Research Brief]. National Council of Teachers of Mathematics. Retrieved from https://www.nctm.org/Research-and-Advocacy/Research-Brief-and-Clips/ Involving-Latino-and-Latina-Parents/

Ishimaru, A., Barajas-López, F. \& Bang, M. (2015). Centering Family Knowledge to Develop Children's Empowered Mathematics Identities, Journal of Family Diversity in Education ,1(4), http://familydiversityeducation.org/index.php/fdec/article/view/63

Lopez, C. O., \& Donovan, L. (2009). Involving Latino parents with mathematics through family math nights: A review of the literature. Journal of Latinos and Education, 8(3), 219-230.

Oliver, M. \& Shapiro, T. (1995). Black wealth/White wealth: A new perspective on racial inequality, Routledge.

Yosso*, T. J. (2005). Whose culture has capital? A critical race theory discussion of community cultural wealth. Race ethnicity and education, 8(1), 69-91. 


\section{Additional Resources for Parents and Schools}

- Math and Parent Partnerships with Schools (MAPPS) https://mappsua.wordpress.com/

- UofA Remote Learning Resources: for Parents https://crr.math.arizona.edu/remotelearning-resources

- DREME Early Childhood Mathematics at Home, some articles applicable to early elementary (English y Español): https://dreme.stanford.edu/news/home-early-mathlearning-kit-families-ideas-supporting-young-children-s-math-skills-during

- PBS Summer of Learning! (Always free): https://www.kqed.org/education/ athomelearning

- Examples and ideas of how to talk math with your kids: Talking Math with Kids

- California Department of Education has resources in Spanish and English for parents: https://www.cde.ca.gov/re/CC/mathinfoparents.asp 